\title{
Autism and Schizophrenia Are Disorders of Evolvability
}

\author{
C. Thomas Gualtieri \\ North Carolina Neuropsychiatry, PA, Attention \& Memory Centers, Chapel Hill, Charlotte, and Raleigh, NC, USA \\ Email: tg@ncneuropsych.com
}

Received December 5, 2013; revised January 5, 2014; accepted January 12, 2014

Copyright (c) 2014 C. Thomas Gualtieri. This is an open access article distributed under the Creative Commons Attribution License, which permits unrestricted use, distribution, and reproduction in any medium, provided the original work is properly cited. In accordance of the Creative Commons Attribution License all Copyrights (C) 2014 are reserved for SCIRP and the owner of the intellectual property C. Thomas Gualtieri. All Copyright (C) 2014 are guarded by law and by SCIRP as a guardian.

\begin{abstract}
Autism and schizophrenia are of particular interest because new developments in genomic medicine address three aspects of the conditions that have been difficult, thus far, to resolve: their heterogeneity, from subclinical manifestations to disorders that are gravely disabling; the genetic basis for their high heritability; and the persistence of disorders in light of their high heritability but low reproductive success they convey. The origins of autism and schizophrenia, their persistence and heterogeneity can be understood by integrating information from genomic science, the social brain and the evolution of socialization, intelligence and language. Both conditions are associated with structural changes in the genome, specifically copy number variants. Such systemic mutations contribute to an unstable and mutable genome and have been especially notable during primate > hominid evolution. Along with mechanisms that affect gene expression, they contribute to a genome characterized by variability and evolvability. A dynamic and variable genome is reflected by a high degree of phenotypic variation. This, in turn, is reflected in the diversity of neurodevelopmental disorders, in particular autism and schizophrenia. Evolvability is more than a dispositional concept, it is a trait in its own right. In the special case of hominid evolution, evolvability has been both an independent and a dependent variable. Evolution of the modern human brain seems to have arisen during the cultivation of unstable regions in the genome that were conducive to a high degree of inter-individual and inter-generational variation. The consequence of even small aberrations in evolutionary processes and phenotypic variations is most likely to be manifest in the functions of the social brain: self-referential processing, perspective taking and the dual components of empathy; also language as well as intelligence itself. The trade-off is a dynamic genome that can rearrange itself in untoward ways and may be felt in one or more of the above functions. The occurrence of neurodevelopmental disorders ranging from the learning disabilities and ADD to autism and schizophrenia, are epiphenomenal to a genome that is unstable and mutable. The selective advantage of such a genome is the runaway evolution of positive prosocial and intellective traits. If there is a core to the pathology that emerges in autism and schizophrenia, it is at the genomic level, and is probably related to the unique evolvability of the human genome. Genetic transformation as an agent of evolvability is necessarily associated with untoward consequences. Just as point mutations may have deleterious effects, so do genomic transformations. The neurodevelopmental disorders, therefore, are the consequence of evolvability.
\end{abstract}

\section{KEYWORDS}

Autism; Schizophrenia; Genomic Transformation; Copy Number Variants; Social Brain; Evolvability

\section{Introduction}

Although autism and schizophrenia are distinct disorders, with only a small amount of clinical and genetic overlap, they have certain features in common. One is their heterogeneity. Within each group, patients differ in virtually every salient characteristic, including symptomatology, intellectual and functional abilities, neurocognitive strengths and weaknesses, neuropathological correlates, prognosis and response to treatment. A second commonality is their particular association with aberrant modes of thought, disordered communication and deficits in social relating. Autism and schizophrenia are both global afflictions of the highest reaches of brain organization 
and although they are very different, with respect to etiopathogenesis, they are both mysteries.

There is another element that the two conditions share: they are both highly heritable disorders but they are also associated with low reproductive success. The inevitable question, then, is why they exist at all. One would expect them simply to have gone extinct. Nevertheless, both conditions occur in all corners of the world with similar frequency and as far as we can determine they always have.

The origins of autism and schizophrenia, their persistence and their bedeviling heterogeneity can be understood by integrating information from genomic science, the social brain and the evolution of socialization, intelligence and language. If the data cohere sufficiently to warrant a theory, it is that the evolution of the highest components of human psychology was generated by an unstable and mutable genome that is also prone to occasional but potentially devastating errors, and that such errors are the consequence of genomic transformations. The idea I propose is that autism and schizophrenia aredisorders of evolvability [1,2].

\section{Neurodevelopmental Disorders}

The premise is that autism and schizophrenia are both neurodevelopmental disorders, conditions with an origin in gametogenesis or embryogenesis affecting neural development and plasticity [3]. Such conditions tend to be diverse in their clinical characteristics and prone to high rates of co-occurrence with other neurodevelopmental conditions. They are highly heritable but studies have only discovered multiple genes that are probabilistic in their association with the disorders and that are frequently associated with more than one neurodevelopmental disorder.

The neuropathological correlates of the neurodevelopmental disorders are as diverse as the conditions themselves and the number of identified candidate genes: for example, aberrations in neuronal survival, differentiation and migration, connectivity, specification of axons and dendrites, myelination, growth processes, innervation of target cells, programmed cell death, synaptogenesis, the organization of effective and efficient neural networks and so on. Gross abnormalities in brain architecture are associated with severe mental handicap, sensory and motor impairments of the first order and intractable epilepsy. Most of the neurodevelopmental disorders, including ADHD, the learning disabilities, autism and schizophrenia have been associated with morphological aberrations in the brain but the differences from normal are small, inconsistent and non-specific.

Autism is a prototypical neurodevelopmental disorder. Schizophrenia is not so clearly defined as such, and although substantial evidence has accrued to suggest that schizophrenia is a disorder of brain development and plasticity, other hypotheses are also current [4]. The neurodevelopmental hypothesis of schizophrenia asserts that the underlying pathology has its roots in brain development even though the full impact of the abnormalities may not be manifest until adolescence or early adulthood [5-7]. The delayed onset of schizophrenic symptoms and deficits may be a function of epigenesis or heterochronic genes or it may reflect the vulnerability of disordered neural networks to environmental events.

New developments in genomic medicine have proven to be particularly salient to the neurodevelopmental disorders. With respect to autism and schizophrenia, they address three aspects of the conditions that have been difficult, thus far, to resolve: their heterogeneity, ranging from subtle, subclinical manifestations to disorders that are gravely disabling; the genetic basis for their high heritability; and the evolution of the disorders in light of the low reproductive success they convey.

\section{Genomic Disorders}

Traditionally, the category of genetic disease has referred to inherited traits that segregate in a Mendelian fashion and result from base pair changes that alter an encoded protein's structure, function or regulation. Genomic disorders are different; they are caused by structural changes in DNA that occur by virtue of architectural features of the genome that render a portion of it unstable [8-10]. As a rule, the normal copy number of a gene is two, one copy inherited from each parent. However, since the advance of whole-genome assays by array or DNA sequencing technologies we have learned that genomic transformations, including rearrangements resulting in alterations from the normal gene copy number, are quite common. They also happen to be related to CNS disorders that present as neurodevelopmental disorders in early life or in later life as psychiatric disorders or neurodegenerative disease [11]. Such conditions are heritable although they may also occur sporadically $[12,13]$.

Thus a theory of genomic disorders has emerged. In such conditions, the conveyed clinical phenotype does not result from a point mutation, but rather from structural rearrangements of DNA sequences within or among the chromosomes. The structural variations that ensue may be deletions or duplications of a DNA segment, or balanced rearrangements such as inversions and translocations [14]. Collectively they are known as copy number variations (CNVs). Examples of specific genomic disorders are the Williams syndrome and the SmithMagenis syndrome, genomic disorders caused by deletions. Charcot-Marie-Tooth disease type 1A is related to a duplication [15]. Disorders with such structural variations may be caused by dosage effects of single or multiple genes [16]. 
Although the mechanism(s) that govern such events are not well understood, genomic transformations, and in particular rearrangements, tend to occur in unstable regions of the genome identified by the occurrence of region-specific repeat sequences, called "low copy repeats" (LCRs, or segmental duplications, SDs) because they are not highly repetitive. LCRs can contain one or multiple genes, pseudogenes, gene fragments, retroviral sequences, regulatory regions, or other paralogous segments [17]. LCRs are often found in pericentromeric and subtelomeric regions of human chromosomes [18], but they may also be found in interstitial regions. The size, relative orientation, distance between copies, and shared percent identities of the LCRs are factors that render the genomic region susceptible to rearrangement and probably influence the type of rearrangement which occurs [19].

Such structural changes (CNVs) are present across the entire human genome and they often contain partial or complete gene sequences. They occupy about $12 \%$ of the human genome and they occur in normal, healthy individuals as well as in association with disease [20,21]. In fact, most of the bases that vary among genomes reside in CNVs [22,23] and population-based surveys have identified thousands of them. Their functional impact has been demonstrated across the full range of biology [24], from cellular phenotypes such as gene expression [25], to all classes of human disease with an underlying genetic basis: sporadic, Mendelian, complex and infectious [26, 27]. Genome-wide studies have indicated the extraordinary impact of these processes and our own species is remarkable for numerous large segmental duplications $[28,29]$.

Since at least half of the CNVs detected so far overlap with protein-coding regions (Sebat et al., 2004) they affect the behavior of genes. One member of a pair of duplicated genes may retain its original function while its paralogue either disappears by accumulation of detrimental mutations or acquires beneficial mutations that confer new, positively selected functions [30]. CNVs can directly influence gene dosage, the number of copies of a gene in a cell; thus, gene expression can be altered by higher and lower gene dosages [31]. Deletions are capable of removing a gene entirely or they can result in the unmasking of a recessive allele that would normally not be expressed. CNVs can also affect gene expression indirectly by interacting with regulatory elements [32].

$\mathrm{CNV}$ burden is relevant to perennial problems that have complicated the study of neurodevelopmental disorders in particular and neuropsychiatric disorders in general: the problem of syndromic heterogeneity, the diversity of the conditions, their occurrence in pure form in small numbers of individuals and in partial or subclinical forms in a great many more; the problem of comorbidity, the co-occurrence of elements of more than one disorder in an individual; the problem of heterochronicity, the appearance of one condition at a point in time and then a transition to another later on; and the problem of familial diversity, the fact that most such conditions do not "breed true" but are present in different forms in family members [33,34]. And as it happens, autism and schizophrenia are two neurodevelopmental disorders that possess all of these qualities and that also carry a comparatively high CNV burden [35-40].

The CNVs that are statistically over-represented in schizophrenia are also significantly associated with other disease phenotypes. For example, the 22q11 microdeletion is associated with schizophrenia and Velocardiofacial syndrome [41], as well as anxiety, depression, attention-deficit hyperactivity disorder, obsessive-compulsive disorder and autism spectrum disorders [42]. Deletions and duplications at 1q21 are associated with schizophrenia $[43,44]$ and multiple pediatric phenotypes, including developmental delay and congenital malformations [45, 46]. Deletions at 15q13.3 are associated with schizophrenia, generalized epilepsy $[47,48]$ and mental retardation [49]. Similarly, microduplications of 16p11.2 are found to be significantly associated with schizophrenia, autism, and bipolar disorder [50,51]. The majority of genes thus identified are disproportionately associated with pathways important for brain development, including synaptic long-term transmission, neuregulin and integrin signaling and axonal guidance [52].

\section{A Dynamic Genome}

Genomic transformations are associated with susceptibility to disease, especially neuropsychiatric disorders, but also cancers and even infectious diseases. But that is not their primary role; like genetic mutations, they can have deleterious consequences, but their role in biology is to foster inter-individual genetic variations as well as variation from one generation to the next [53-55].

Although CNVs were at one time thought to be rare among healthy individuals, they are now recognized as a major source of inter-individual genetic variation There are at least 255 loci across the human genome that contain structural variations among unrelated individuals; no fewer than 24 were found to be present in $>10 \%$ of normal individuals. Half of these regions overlap with genes, and many coincide with segmental duplications or gaps in the human genome assembly [56]. Thus they are central to reproductive fitness and speciation. Disease susceptibility are the occasional untoward consequences of a dynamic and inherently unstable genome.

CNVs represent one of the most dynamic forms of human genetic variation from one generation to the next [57]. The rate of de novo CNVs from one generation to the next seems to be higher than the rate of new base mutations (approximately $1.7 \times 10^{-6}$ per locus per gener- 
ation for CNVs compared with $1.8 \times 10^{-8}$ for sequence variations) [58]. Locus-specific mutation rates for genomic rearrangements appear to be two to four orders of magnitude greater than nucleotide-specific rates for base substitutions [59]. What we have, therefore, is a mechanism of structural rearrangement that allows multiple forms of a gene to co-evolve and to rapidly reorganize the genome [60,61]. The fact that the amounts and types of repetitive DNA varies between organisms may reflect how rapidly a species is capable of evolving to changes in its environment. Such benefits, however, come with risks. For example, repetitive DNAs serve as substrates for chromosomal rearrangements that include diseasecausing deletions, inversions, and translocations [62].

Genomic transformation as an agent for adaptive change appears to be a recent development. Pre-primate evolution was largely driven, it seems, by point mutations or whole-genome duplication. Compared with other mammals, however, the genomes of humans and other primates show an enrichment of large, interspersed segmental duplications (SDs) with high levels of sequence identity. During primate and hominid evolution there seems to have been an excess of genomic rearrangements, providing ample substrate for novel juxtapositions and selection. Studies have also suggested a nonuniform rate of duplication throughout primate evolution with an excess of the duplication rate at the time of the hominoid common ancestor [63]. Most of the known recoding editing events in mammals occur in brain-specific genes that have gone through multiple gene duplication events generating sequence-related sub-units and whose primary transcripts are also subject to a high degree of alternative splicing [64].

Man, gorilla, and chimpanzee likely shared an ancestor in whom the fine genetic organization of chromosomes was similar to that of present man. Eighteen of our chromosome pairs are virtually identical to those of orangutan, gorilla, chimpanzee and our presumed common hominoid ancestor and the remaining pairs are only slightly different [65]. We share 98.5\% homology at the DNA level and $99.4 \%$ identity at functionally important regions [66]. Recent research, however, has revealed more genetic dissimilarity between humans and the great apes than anticipated on the basis of high-resolution chromosome analysis, leading to the identification of novel human genes, many of which lack antecedents in other mammalian species, and suggesting mechanisms of evolutionary plasticity [67]. In fact, almost all of the genetic differences between humans and other primates are a result of duplications, deletions, inversions and transformations [68,69]. The unstable regions of human and higher primate chromosomes that generate CNVs, therefore, suggest "gene nurseries" that could play a major role in gene innovation and speciation [70].
Genomic re-arrangement accounts not only for the occurrence of neurodevelopmental disorders and their heterogeneity but also for inter-individual genetic variability, the sine qua non for what is called evolutionary adaptability, or "evolvability" [71]. Genomic rearrangements through creation of novel fusion/fission genes, rather than single nucleotide mutations, has been proposed as the major driving force for hominid evolution [72-75]. There are other processes of genomic transformation that are also salient to genetic variability and many if not most are also related to neurodevelopmental disorders. Genetic transformation as an agent of evolvability is necessarily associated with untoward consequences. Just as point mutations may have deleterious effects, so do genomic transformations. The neurodevelopmental disorders, therefore, are the consequence of evolvability.

Because genomic changes, especially rearrangements, have occurred at an accelerated rate during hominid evolution, I shall consider their salience in light of the major changes that distinguish human beings from the higher apes. Those characteristics fall into four categories: our intense and cooperative sociality, our creative intelligence and language as an agent of affiliation, and distributed intelligence. These three elements are properly considered in terms of evolutionary and theories of a social brain; they are particularly relevant to the problems of autism and schizophrenia. The fourth category is fine motor control and coordination, much more highly developed in humans than in any other animal, and essential for speech, tool-making, hunting, art and warfare. It is not a category I shall dwell upon but it is not irrelevant to the clinical state of patients with neurodevelopmental disorders.

\section{The Co-Evolution of Socialization, Intelligence and Language}

Four elements arose among the hominids during the $5 \mathrm{M}$ years or so that separate humans from our closest primate cousins. They all exist, in rudimentary or stereotyped forms, among many animals, but they simply flourished during the evolution of the hominids. Their co-evolution occurred with extraordinary rapidity. The time line of the Cambrian explosion, when most major animal phyla appeared lasted more than $50 \mathrm{M}$ years; contrast that to hominid brain growth from australopithecine to human in about 2 million years.

Cooperative socialization, intelligence and language are not discrete evolutionary lines. Language is, in essence, a device for information transmission. Intelligence is an information storage and processing unit. The human brain is large enough to do a lot of processing and to store a great deal of data, but its capacity is finite. The capacity of 150 human brains is much better, so in pri- 
mate societies it was a distinct advantage to develop what is called distributed intelligence. Society and culture are also information storage and processing units, but with a much higher capacity and a greater degree of flexibility than individual units. Intelligence, therefore, is not limited by the "skin and skull" of the individual, but also relies on the resources and materials in one's social environment [76]. Societies that are based on distributed intelligence require an efficient information-sharing system, and that is language. Over a span of $2 \mathrm{M}$ years, therefore, socialization, language and intelligence coevolved, all related, all essential one to the other, and no one of them independent or autonomous [77]. No one can be said to be primary or secondary and no one was caused by any of the others. They came about together, and it is hard to imagine how it could have happened in any other way.

Compared to other mammals of equivalent size, primates have brains that are approximately twice as large, and the relative volume of neocortex (relative to the rest of the brain) correlates with the mean group size typical of that species. Larger group sizes correspond to larger neocortical volume [78]. Large brains, like large social groups, have certain advantages. But brains, like groups, are expensive in terms of resource consumption. In fact, brain accounts for eight to ten times more energy per unit mass than the average for the body as a whole [79]. There has to be some benefit, proportionate to the expense, to make a large brain worthwhile. In phylogenetic terms, the benefit is that bigger brains are more intelligent. Across the phylogenetic scale, social learning, innovation, and tool use frequencies are positively correlated with a species' relative and absolute neocortical brain volumes [80]. There is also a positive correlation between brain size and IQ in humans [81]. A number of researchers have argued that the increase in brain size is intimately linked to another distinctive feature of the primates: their intense sociality, and female sociality in particular [82-84].

Although early explanations for hominid brain growth emphasized the brain's role in sensory or technical competence (foraging skills, technical innovations, and wayfinding), the balance of evidence now clearly favors the suggestion that it was the computational demands of living in large, complex societies that selected for large brains [85]. It has been argued that the increase in brain size was far in excess of what was required to flake rocks into tools, to hunt large animals and to find one's way around the savannah without getting lost. The size of hominid brains is well in excess of what is required just for environmental mastery. It must have been the "computational demands of living in a complex society" that drove selection for large brains. For example, in successful groups, competition has to be balanced with co- operation. One has to discern whom to trust and who is a faker. Individual decisions have to be responsive to decisions made by other group members. One's choices must serve not only one's own bioenergetic needs, but must also permit other group members to meet theirs [86,87]. Thus the idea that brain and intelligence increased so robustly in so short a time because of the intense sociality of the hominids (Chance \& Mead, 1953) [88]. This is called the social brain hypothesis [89].

Different aspects of primate socialization have been emphasized and, inevitably, controversies have arisen [90]. For example, the Machiavellian intelligence hypothesis is based on the premise that animals living in permanent social groups necessarily compete for scarce resources, and successful competition involves the ability to 'out-wit' other group members [91]. If an individual can anticipate how another will behave in certain circumstances he or she will be able to manipulate or control the outcome. Many animals have evolved the capacity to deceive but primates engage in deception in a knowing way. Chimps, in particular, exhibit deceptive strategies that are uncannily human. This capacity has been suggested as the evolutionary origin for theory of mind. It is easy to imagine how Machiavellian intelligencecan trigger a cascade of increasingly elaborate cognitive counter-strategies. It reflects the cognitive demands involved in tracking a complex web of relationships through time and forming coalitions and alliances. The presumption is that primates are biologically prepared for forms of social engagement that require the mental representation of abstract concepts, like social bonds and alliances, in order to negotiate the social landscape [92].

It is neither necessary nor compelling to consider the social brain hypothesis simply in terms of dominance and deception. Individuals in social groups compete for resources, it is true, and males compete for access to receptive females. Size and strength do not always win the day, at least among the chimpanzees; sometimes, smaller males will band together to win out, and one presumes they are the clever ones. But cooperative behaviors are not only favored because they enable a more efficient exploitation of others. Individuals in primate societies are also interdependent, and cooperation provides positive benefits for both donor and recipient. In fact, reciprocity and altruism are consistently met with in primate societies, even ours, although some academics are understandably slow to recognize this. In the games that evolutionary economists like to play on their unwitting undergraduates, strong prosocial tendencies are usually found to characterize human behavior: reciprocity, for example (an economically irrational willingness to cooperate in the absence of any personal incentives) and altruistic punishment (an economically irrational desire to punish 
miscreants at a cost to oneself) [93,94].

A consensus is developing to the effect that, for primates at least, the benefit of a large brain comes from the capacity to create and maintain complex societies that provide individuals with much more effective means for solving the problems of everyday survival and reproduction [95]. In fact, it is likely that cooperation, interdependence, altruism and reciprocity were not only conducive to the growth of brain size, but a necessary condition. This is illustrated by the obstetrical dilemma, the fact that a large-brained infant challenges the capacity of the primate birthing process [96,97]. The pelvis of a bipedal primate only allows the passage of a small cranium, but if hominid females evolved a larger pelvis it would challenge the biomechanics of upright walking. If the human cranium is ultimately to contain a big brain, the infant must necessarily be born prematurely. Compared to other primates, therefore, the human newborn is twelve weeks premature. Alternative explanations have been proposed for the relative immaturity of the human infant [98] but the upshot is the same: even as the child's brain grows at an extraordinary rate in the first twelve months of life, his body is helpless, and the mother who takes care of him lives in a precarious state.

This event occurred during hominid evolution from the australopithecines. Lucy, whose fossilized skeleton was discovered in Ethiopia in 1974, walked upright, but she had the cranial capacity of a chimpanzee, about $400 \mathrm{cu}-$ bic centimeters. It is believed that the australopithecines gave rise to genus Homo about 2 million years ago and the first hominid was Homo habilis, whose brainvolume was about 750 cc. Then there was Homo erectus, whose brain volume was about $900 \mathrm{cc}$, and then Home sapiens, about 1600 cc. As the hominid brain grew in size, the hominids themselves grew larger; they became fully bipedal and developed complex social structures, protolanguage, sophisticated tools, clothes to wear and, at some point, monogamous pair-bonding strategies. In short order they succeeded in peopling the Eurasian landmass at the same time their females and young were consigned to prolonged periods of helplessness and inutility. Another extraordinary cost generated by their big brains, and a cost that could only be met only by a group acting with mutuality and cooperation.

An insight on the evolution of large brains by Lindefohrs et al is the calculation that males and females exercise differential effects of brain growth [99]. As it happens, the relative number of males and females is different in different primate groups. Comparing brain volumes and the relative volumes of different parts of the brain, Lindefohrs demonstrated that the number of females in a primate group correlates positively only with the relative size of the telencephalon and especially with neocortical volume, but not with the volume of other major brain regions. In contrast, the number of males correlates positively only with the relative size of the diencephalon (which includes the limbic system and the hypothalamus). This concurs with evidence from genomic imprinting that neocortical size is inherited maternally, but the limbic system is paternally inherited [100]. The idea is that male and female brains have responded to different kinds of social pressures: females to social integration, males to male-male competition and fighting.

Hominid females were larger relative to males than subhuman primate females and human females are the largest of all. So presumably, our African Eve was better equipped to endure the risk of carrying a helpless infant; and better equipped, one supposes, to assert cooperation as a social value for the band [101]. She also insinuated a larger neocortex into her male and female progeny, with its particular capacity for prosocial behaviors: communication and understanding, reciprocity, planning and temporal processing. Primate sisters have always been socialized; cooperative care of the young, for example, is the rule among them. Among the hominids, the brothers were socialized as well. In the origins of our kind, social cooperation and inter-dependence co-evolved with a large brain [102].

\section{Runaway Evolution}

The SBH assigns primacy to socialization in hominid evolution, while the nature of a positive feedback loop is that no one element has primacy but that each element responds to changes in every other. The essence of runaway evolution-and that is what occurred among the hominds-is a self-reinforcing process, a kind of genetic perpetual motion machine.

Runaway evolution is the persistent increase (or decrease) in a mean trait value; that is, with succeeding generations, a particular trait or collection of traits increases in strength by virtue of a positive feedback loop. Runaway processes in evolution were originally proposed by Fisher as a solution to a vexing problem in sexual selection, the female preference for male ornamentation-e.g., the peacock's train-that is so clearly disadvantageous from every perspective aside from attracting females. Fisher proposed that the evolution of odd mating preferences is self-reinforcing because the offspring of such matings inherit two characteristics: the capacity for elaborate sexual ornamentation from the father and a preference for same from the mother [103]. The process, however, is only successful when ornamentation indicates the individual's underlying fitness; he has sufficient resources to waste some on mere display. It is also creates new species rapidly by virtue of sexual isolation and phenotypic divergence of a population from its nonornamented and non-preferring relatives [104]. 
With respect to something more transcendent than elaborate sexual display, that is, brain growth, the feedback loop is this: larger brains > more complex social groups > even larger brains [105,106]. The analogy is that a large brain entails certain liabilities that are more than compensated by the individual's capacity for socialization, intelligence and communication. These, we must assume, are the qualities that hominid females preferred. Thus, once bands of hominids committed to cooperation in the care of immature infants and the provision of highenergy foods to nursing mothers, evolutionary success was driven by the quality of the interdependent relationships within the bands. A virtuous cycle, therefore, ora runaway process: higher intelligence required more supportive social structures which in turn stimulated the growth of intelligence.

It is not possible to assign primacy to one particular aspect of a congeries of evolutionary changes that occurred a million years ago. The fact is that they all happened-socialization, intelligence, communication and fine motor dexterity-and more or less at the same time. That their evolution is related to genomic transformations of various kinds is evidenced by a peculiarity of phylogenetics, where such events seem to be concentrated during primate $>$ hominid evolution; and from medical genetics, where they are noted to occur in disorders of the social brain. That they are strongly interrelated is illustrated by the architecture of the social brain, which is predominantly mediated by overlapping and interconnected structures.

\section{The Neural Architecture of a Social Brain}

The social brain hypothesis, as a theory of human evolution, dovetails with social brain as an element of brain organization. Over the last two million years, the brains of our more recent ancestors increased greatly in size, especially in the prefrontal, posterior parietal, lateral temporal, and insular regions. Specialization of the two cerebral hemispheres for related, but different functions became pronounced, an event that was most pronouncedinthe development of language [107]. The social brain hypothesis in evolution relates the growth of intelligence and the differentiation of the hominids from other primates to affiliation and communication. The social brain in cognitive neuroscience instantiates this process.

The functions of the social brain have been variously divided but are more readily distinguishable in theory than in fact. That is because they are closely related; one must suppose that they co-evolved. The locations of those functions are widely distributed in the frontal, temporal and parietal cortices, the cingulum, and to a degree in the striatum and cerebellum; their cerebral addresses are largely overlapping. It is common to divide those functions into two broad categories, the cognitive (i.e., social cognition) and affective (empathy) and to maintain that the latter arose earlier in phylogenesis. The origins of empathy, however, were probably communicative, as a fast signaler of salient information among groups of small animals. The social brainmay be defined in terms of three operations:

1) Self-referential processing: I am an individual with thoughts and feelings;

2) Perspective taking: You are an individual with thoughts and feelings similar to my own; and

3) Empathy: A connection exists between me and thee comprised of thoughts and feelings.

The three operations of the SB are sometimes subsumed under different names: social intelligence was coined by Thorndike in 1920 [108], who defined it as the ability to perceive one's own and others' internal states, motives and behaviors, and to act optimally on the basis of that information. Emotional intelligence is a closely related term and more recently, social cognition. Implicit in the terms is an individual's ability to be aware of and express emotions, to be aware of others' feelings, to establish interpersonal relationships and to manage and regulate emotions. Implicit also are the dual cognitive and affective orientations of the SB, which Adam Smith identified in 1759 when he distinguished intellectualized sympathy, the ability to recognize the emotional experiences of others, and instinctive sympathy, the ability to experience their mental state oneself [109]. In current research, the cognitive side of the SB includes theory of mind, social knowledge, attributions and cognitive empathy and on the affective side, emotional perception, processing and empathy [110].

The first two operations of the SB are cognitive in nature, although they also play a role in generating or modulating emotional responsiveness. They are well-defined in terms of cortical circuitry, while the third operation, empathy, is a more distributed system involving cortical and subcortical regions [111]. The first operation, selfreferential processing, is self-awareness, one's "narrative" or "autobiographical self”. It also happens to represent the "default" mode of brain activity, that is, a system that is most active in the brain when it is at rest. When one engages in goal-directed activity-when one is doing something - the metabolic activity of the dorsal-medial PFC actually goes down. What it is said to be doing during this down-time is "processing elements that are integral to aspects of the self" [112]. The second operation of the social brain is perspective-taking, the ability to appreciate that another individual is thinking or feeling and his motivations for what he is doing. Theory of mind, believed by some to be a central deficit in autism and impaired in many other neuropsychiatric disorders as well, is the second operation.

The first two operations of the SB reside incortical 
midline structures, the medial PFC and posterior cingulate/precuneus. Self-referential processing occupies thedorsal medial PFC [113-117]. Perspective taking is also concentrated in the medial PFC, but in a ventral position $[118,119]$. The two frontal regions that are involved with self and other, therefore, are very close and tend to work together, although the dorsal region is more active when one is thinking about oneself, and the ventral regions when one is thinking about others.

The parietal lobes also contribute to social cognition. The PL participates in self-awareness and perspectivetaking, although in a different dimension. Because they are close to visual association areas, their particular functions in self- and other-awareness are largely spatial in nature-where one is in space, and where one's various parts are in space. They are also occupied with agency: self-agency is knowing when we are doing something ourselves and external agency is knowing that someone else is doing it. In functional imaging studies, subjects contemplating themselves performing an action activate their left PL. When they contemplate the same action performed by a third person, they activate the right [120, 121].

Not only are the PFC and PL the newest parts of brain in evolutionary terms, but they are the most active and energetic part of the brain in metabolic terms. In bioenergetic terms, they are the most expensive part of brain to maintain. They share their domicile in the cerebral cortex with the functions of reasoning, the executive functions and working memory and also with our most important regulatory apparati. The regulation of emotion, the entraining of physiological functions like heart rate and respiration and even the secretion of endocrine hormones are also governed by the same structures that are believed to comprise the frontal and parietal regions of the social brain. Since these areas have shown "disproportionate expansion in recent evolution" [122]. One may be forgiven for believing they are still in the betatesting stage. Think of them as Evolution's latest and greatest new technology and you won't be surprised at how prone they are to programming errors.

Of the three operations of the SB, the first two, selfreferential processing and perspective-taking, are largely cognitive in nature while the third, empathy, is more affective. Empathy resides in phylogenetically older brain regions, and during evolution it has evolved, first as a system for communication and then as an agent of affiliation.

Empathy is an individual's capacity for shared emotion, the ability to feel what someone else is feeling, as if it were happening to himself. Empathy isn't an emotion per se, but rather a function that allows a person or an animal to mirror the emotional state of a conspecific. Empathy is such an essential function, at least for social animals, that it is proper to think of it as an instinct, as Adam Smith did. Human beings aren't much given to instinctive behaviors, but empathy can be considered an instinct because it is automatic, it doesn't require conscious processing, it's something we are born with and it is necessary for our survival as individuals and as a social species.

In contrast to the cognitive operations of the social brain empathy is much older. It is the only operation that reliably occurs in lower animals. Self-referential processing has been observed in chimpanzees, but inconsistently. Chimps may also possess theory of mind, and much has been made of their Machiavellian behavior; like their capacity for learning sign language, however, it is a rudimentary ability compared to humans. In contrast, there are numerous observations of even small mammals and birds showing empathy for their fellows. A group of mice, for example, seeing one of their number being dealt with harshly, will exhibit signs of personal distress. Emotional contagion, a primitive manifestation of empathy, is common among mammals and birds.

Empathy then is a phylogenetically older system and one assumes that it is a simpler system because it happens more quickly than the cognitive operations of SB, it is often involuntary and virtually instinctive. If one refers to it as a "simpler" system, though, that is not reflected by the demonstration of clearly defined circuitry. Unlike the first two operations, residing in circumscribed regions of the PFC and PL, it has not been possible to identify an empathy circuit in human or animal brain. It's simplicity is reflected by its close association with emotional perception per se. The expression of emotion is an efficient communicator that entails the concomitant development of an emotional receiver; in humans, this is experienced as empathy. One might think of empathy as an emotion receiver, or, better, an emotion resonator. It exists to capture the signals emitted by an organism on the emotional channel.

Feelings and emotions are signaling devices in the brain; feelings are internal signals, like the pain one feels when she touches a hot burner. Emotions are external signals: saying, Ouch, and wearing a pained expression on one's face. In consequence to that painful feeling, one emits a signal by expressing the appropriate emotion [123]. The feeling of pain is a fast operator, an extremely efficient communication device, and it signals the appropriate action step—hand withdrawal—without seeking permission from one's PFC.

The neural basis for empathy is subcortical as well as cortical, comprising a distributed system with perceptual modes operating in parallel and identified with the sensory apparatus in general and with emotional perception in particular. The perception of a social/emotional event activates the primary sensory areas but then proceeds to 
highly specialized association areas. Wernicke's area, for examplein the posterior superior temporal gyrus (and possibly also the posterior middle temporal gyrus) and can initiate the decoding of phonemes with amazing facility (20 - 30 phonemes in a second) [124]. In the superior temporal sulcus there is a collection of regions that are activated in response to biologically and socially salient visual motion stimuli [125]. In monkeys and humans, the STS is activated by movements of the eyes, mouth, hands and body, suggesting that it is involved in the analysis of biological motion [126].

Functional imaging studies have also found responses to static faces specifically in the fusiform gyrus. Perception of invariant features of faces, such as identity, relies heavily on the fusiform gyrus, whereas perception of changeable aspects of faces, such as gaze and expression, relies more on regions in the STS. The representation of invariant aspects of faces underlies the recognition of individuals, whereas the representation of changeable aspects of faces, such as eye gaze, expression, and lip movement, underlies the perception of information that facilitates social communication. Neural systems for other cognitive functions can be recruited to act in concert with the regions in the core system to extract meaning from faces [127,128].

The subsequent analysis of socially relevant stimuli is believed to occur in the amygdala and orbitofrontal cortex. The principal function of the amygdala appears to be the linking of perceptual representations to cognition and behavior on the basis of the emotional or social value of the stimuli. Structures in close proximity to the amygdala, such as temporal polar cortex and perirhinal cortex, also contribute to social cognition [129].

Social perception is "embodied" in mirror neurons residing in the ventral PFC and inferior PL [130]. It is assumed that the mainfunctional role of parietofrontal mirrorneurons is to understand motor acts performedby others in an automatic way, that is, by matching them to one's own motor repertoire [131]. Evidence has also accrued, however, similar neural circuits are stimulated when humans experience emotions and when they perceive others expressing emotions. The anterior insula, for example, is activated in response to the sight of disgusted facial expressions of others as well as by the first-handexperience of disgust [19,132]. When participants are required to observe or to imitate facial expressions of various emotions, increased neurodynamic activity is detected in the STS, the anterior insula, and the amygdala, as well as in areas of the premotorcortex corresponding to the representation of faces [20,133]. Another study showed that the observation of everyday hand and face actions performed with an emotion recruits regions involved in the perception and the experience of emotion and/or in communication [21,134]. The authors of that study speculate that, inaddition to inducing resonance in the motor program necessary to execute an action, watching an actionperformed with emotion induces a resonance in the emotional system responsible for the affective modulation of the motor program. Such a mechanism could also be a key to understanding how the other person feels and to his or her associated intentions [135]. Clinically, some functional deficits typical of autism spectrum disorder, suchas deficits in imitation, emotional empathy, and attributing intentions to others, have a counterpart in the functions of the mirror system. Evidence of an involvement of the mirror system in autism has been repeatedly reported in recent years [136-138].

Two midline structures, the anterior insula and anterior cingulum, are involved in emotional processing in general and empathy in particular. They contain a unique population of neurons-large spindle neurons-whose function is not yet understood very well. The density of these neurons is highest in humans, next highest in chimpanzees, lower in other apes, and absent in all other species, correlating well with phylogenetic relatedness. Their size and location and the nature of their interconnections enable fast, complex and highly integrated emotional behaviors [139]. They connect different regions that are spatially distant in large brains; possibly, they participate in the integration of sensory, cognitive, and motivational information that is a hallmark of anterior cingulate cortex function [140]. The neural networks that mediate emotional resonance are also closely interconnected with the cognitive parts of the social brain in the PFC and PL.

The neural basis for empathy suggests a basis in sensorimotor intelligence; it is not only diverse and distributed, but exhibits a degree of redundancy that is essential for learning and for social communication and, ultimately, affiliation.

Empathy originated as a mechanism for emotional communication but evolved to become the agent of emotional connectedness, and that is supposed to have arisen in the context of parental care. The cries and whimpers of baby animals, like the smiles and crying of human babies, evoke a virtually immediate response from parents. This capacity for emotional resonance is the second oldest component than the social brain. It was born as a danger signal among the animals. Then it was refined during the long course of evolution and the selfless care of helpless young. It came to be applied outside the context of childrearing and became the basis for our wider network of social relationships. We can say, therefore, that empathy is essential for the regulation of social interactions, coordinated activity, and cooperation toward shared goals [141]. Charles Darwin, who wrote before the word "empathy" was even coined, conflated it with moral sense or conscience.

...any animals whatever, endowed with well-marked 
social instincts, would inevitably acquire a moral sense or conscience, as soon as its intellectual powers had become as well-developed, or nearly as well developed, as in man [142].

Empathy is the agent of affiliation. We feel empathic towards people to whom we are connected. We feel connected to people with whom we empathize. We develop connections to people with whom we share experiences, and the more intense emotional experiences generate stronger connections. Events that excite emotional resonance, whether they are positive or negative, arouse a sense of connectedness to the persons with whom we shared the experience. The affiliations that humans cultivateoccuron the basis of shared emotions and experiences. Affiliation in the sense of belonging to an organization is only a fragment of what the stem means. The Greek word philia conveys friendship, social sympathy, fondness and appreciation for a friend; doing kindnesses; doing them unasked; and not proclaiming the fact when they are done (Aristotle, Rhetoric, II.4).

Affiliation is expressed in clinical matters as relatedness, an individual patient's capacity for mutuality, his ability to interact with other people in a reciprocal way. Autistic children, for example, have a paradigmatic deficit in relatedness. They may be very sweet, and most of them like to be petted or stroked or dealt with gently; they are not automatons. But they are decidedly unempathic. It doesn't matter to an autistic child who is doing the stroking or petting. It is perceived as a pleasant sensation, not as an expression of affection or relating. In the same vein, an autistic child prefers to be at home, but not because it is the heart of the family, but because it is familiar.

\section{The Trait of Evolvability}

The structure and functions of the SB reflect the coevolution of cooperative socialization, intelligence and language. The social brain in evolution has a neural substrate comprised mostly of cortical structures. They are contiguous to or overlap with frontal, parietal and temporal regions that mediate language and that account for the more important aspects of general mental ability. The driver of social brain evolution was a dynamic genome within which various mechanisms, including genetic rearrangement, were conducive to genotypic variability and phenotypic variation. The consequence was an unusual clade evolving not for the purpose of adaptation to a specific niche but rather for adaptability to a range of challenges. The elements that contributed to hominid adaptability-social cooperation, flexible intelligence and effective communication-became in their own right the agents of persistent and ongoing selective pressure.

One must distinguish between adaptability from adap- tation; in quantitative genetics the equivalent terms are variation and variability. Variation is a property of a collection of items that can be observed, while variability is a dispositional concept that describes the potential or propensity to vary [143]. A dynamic genome is a highly variable one because it generates a large number of phenotypic variations in a comparatively short period of time. In this light, adaptation is the observed consequence of natural selection, having generated an organism able to thrive in a particular environment. Such adaptations may be successful for hundreds of millions of years but they are, by definition static events. Adaptability, on the other hand, is a dynamic trait; it is the capacity for an organism, a species or a clade to continuously adapt.

In the terms of evolutionary genetics, evolutionary adaptability is known as evolvability. Evolvability has been defined in different ways, but in essence it is an organism's capacity to develop heritable phenotypic variations [144]. It requires a genome with the capacity to generate intergenerational and inter-individual variability [145]. Selection pressures "choose" among phenotypic variants that are better adapted to the environment generating those pressures. During hominid evolution, one can say that selection "chose" the trait of adaptability. That, after all, is what a large, intelligent brain does. It is eminently adaptable. It is also driven to select for the trait of adaptability. This is an example of runaway evolution [146].

Evolvability, therefore, is more than a dispositional concept but is actually a trait in its own right. In the special case of hominid evolution, evolvability has been both an independent and a dependent variable. It is not only a general characteristic of our lineage that promotes variation, but it also represents, in itself, a trait that is selected for. The evidence that evolvability itself has evolved comes from many sources, but mainly from the fact that both mutation and recombination rates vary across species or clades and are influenced by the genetic makeup of an organism. They are not just the passive consequences of external factors such as the level of background mutagenic radiation but rather an internal factor that influences the occurrence and impact of genotypic variability. The evolvability of a species is said to be determined by constraints on its "phenotypic space”. The makeup of the developmental system of a species, such as having an exoskeleton or an endoskeleton, limits or expands the phenotypic space the descendants of that species can occupy. For example, given the insect bauplan, there are strict limits to the evolution of body size because of the allometric relationships that affect the shape of various organs. The major transitions in evolution clearly affected the evolvability of all descendant clades; consider, for instance, the enormous new volumes of phenotypic space that were opened up by the transition 
from prokaryotic cells to eukaryotic cells; from unicellularity to multicellularity; skipping a few steps, from the concentration of peripheral ganglia to a rostrally-positioned brain; and ultimately from a brain sufficient to meet an organism's instrumental needs to a brain designed for adapatability in a social context [147].

\section{Mechanisms of Transformation}

Evolvability is proportional to genetic variability and phenotypic variation. It is defined in terms of an unstable and mutable genome which cannot be achieved by the mutation of single genes alone. If mutational events that directly affected genomic, protein-coding sequences were the only available molecular mechanism to generate new variants, adaptive evolution would be ponderous and slow [148]. Evolving hominids would still be waiting for such successive mutations to occur, none of which could enhance fitness without the others, or else there would have to be the improbable event of a bout of massive simultaneous mutations [149]. In order to understand the evolvability of social brain in the hominid lineage one must look for dynamic mechanisms that increase genetic variability.

Genetic rearrangement by duplication and deletion is only one of many ways the genome exercises variability and evolvability. There are many others, some that are ubiquitous and others that occur in animals but rarely in plants, others that occur with higher frequency in mammals and still others that are concentrated in higher primates. It is remarkable how frequently transformations of the latter class are associated with neurodevelopmental disorders, especially conditions that affect the development of the social brain.

Phenotypic diversity can be a function of differences in where and when genes are expressed, rather than just the products that the genes encode. [150] Thus, changes in the gene regulatory machinery are also a creative force in morphological evolution [151,152]. In fact, differences in gene expression are probably the real divisor between humans and chimpanzees; our genes are largely the same but the difference is accelerated gene expression changes in the human brain [153]. Genes involved in brain development have a higher tendency to be under positive selection between macaques and humans than between mice and rats [154-156].

The regulation of gene expression involves many different regulatory factors, including the combinatoric actions of transcription factors and other regulatory proteins. Levels of RNA and protein are regulated by transcription and translation, respectively; whether a messenger RNA molecule is translated into protein or not often depends on the presence of RNA-binding proteins that regulate translation. This is a likely mechanism for regulating temporal and spatial patterns of gene expres- sion.

The Fragile $\mathrm{X}$ syndrome, for example, involves abnormal dosage of an RNA-binding protein. Hypermethylation of the expanded CGG repeatsin the 5' untranslated region of the gene FMR 1 causes transcriptional silencing of FMR1 [157,158]. With a full mutation of $>200$ repeats, the result is mental retardation, certain physical characteristics, autism and epilepsy. In an animal model of the FXS, FMR1-null mice have abnormal maturation and pruning of dendritic spines, resulting in dendriticspine morphology similar to that observed in the cortex of patients with FXS $[159,160]$.

Gene expression is modified also by posttranscriptional alterations of messenger RNA by alternative splicing, editing, polyadenylation, localization, transport, or stability [161,162]. There are also forms of RNA that do not code for proteins, the short and long non-protein-coding RNAs, that affect the epigenetic regulation of gene expression [163]. Although the function of most ncRNAs is unknown, it has been suggested that they regulate protein-coding gene expression at both the transcriptional and posttranscriptional level, perhaps by modifying a complementary messenger RNA, by interacting with large histone complexes or complementary DNA sequences, or acting completely independently with no obvious partners [164].

Genetic and epigenetic mechanisms create extraordinary variability allowing the organism to explore a wide range of new variations [165]. Non-coding RNAs can be stimulated by electrical activity in neurons, for example, and such processes are implicated in experience-dependent modulation of neural networks via synaptogenesis and synaptic plasticity. The development of dopaminergic neurons from neural stem cells involves no fewer than 35ncRNAs that are differentially expressed between progenitor and mature states [166]. Non-coding RNAs have also been associated with schizophrenia [167] and the Prader-Willi syndrome [168]. Processes of this kind may explain why more overt signs of autism do not manifest until a later "critical period" of cognitive development and why schizophrenia is largely a condition that arises in late adolescence or early adult life. Such regressions may also account for the inability of neurons and neuronal circuits to properly adapt to environmental stimuli [169].

Another condition associated with altered dosage of an RNA-binding protein important for the processing of small ncRNAs are the 22q11.2 deletion and duplication syndromes. Individuals with The 22q11.2 deletion syndrome- the loss of the q11.2 region from one copy of chromosome 22-have highly variable phenotypes, including the phenotypic constellations that are typically associated with DiGeorge (velocardiofacial) syndrome. Developmental and neuropsychiatric phenotypes asso- 
ciated with the 22q11.2 deletion syndrome include developmental delay, learning difficulties, epilepsy, hyperactivity, anxiety, autism, obsessive-compulsive disorder, bipolar disorder and schizophrenia [170-172]. In fact, the 22q11.2 deletion conveys the strongest DNA-based risk factor identified so far for developing schizophrenia [173,174].

Gene expression exhibits stochastic properties that cause genomically identical cells to vary in the expression levels of individual genes $[175,176]$. Such fluctuations in gene expression profiles have been linked to fast adaptation of organisms to their environment [177]. However, in some cases the pool of cryptic variation generated through epigenetic events, such as minor RNA splice forms or translational mutations [178], can form a basis for long-term adaptation [179,180]. Gene-specific silencing mechanisms such as RNA interference can persist for generations after interference. "Transgenerational environmental effects" on phenotypic variation can occur when environmental factors and genetic variants in previous generations create an epigenetic state that persists across generations in individuals who are not directly exposed to that environment or who do not inherit the original genetic variant. In some cases, environmental exposures lead to heritable epigenetic changes [181,182].

The inheritance of acquired characteristics is the discounted premise of Lamarckian theory. However, there appears to be an alternative mode of inheritance called epigenetic inheritance, which occurs when phenotypicvariations that do not stem from variations in DNA base sequences are transmitted to subsequent generations of cells or organisms. Transmission can occur not only through RNAs, but also by virtue of chromatin marks, including DNA methylation, imprinting and reconfiguration of histones, through self-reconstructing three-dimensional structures (e.g., prions) and self-sustaining feedback loops, metabolic circuits through which different patterns of activity can be maintained and based on transcriptional regulation or protein self-processing [183]. Epigenetic inheritance might allow genetic variants that do not change the mean phenotype to change the variability of phenotype. A heritable genetic mechanism for variable methylation, the loss or gain of $\mathrm{CpG}$ dinucleotides over evolutionary time provides a powerful mechanism for evolutionary adaptation in changing environments that can be mediated epigenetically. The density of CpG islands may vary between individuals due to genetic polymorphisms, presenting an inherited basis of variably methylated regions (VMRs). Epigenetic variationat VMRs influence variation in the expression of nearby genes, which can give rise to large stochastic variability in phenotypes under a given genetic background [184]. This type of genetically inherited stochastic variation may provide a powerful mechanism for evolutionary adaptation to variable environments [185].

There are transposable elements, like retroposons, mobile elements that encode the capacity to move within or among genomes and that account for the expansion of the primate genome over the past $50 \mathrm{M}$ years; the human genome continues to significantly expand due to shifts in retrotrans position activity. One transposable element moves by encoding an mRNA that is reverse-transcribed and inserts elsewhere in the genome. Another excise from its original site and inserts elsewhere [186,187]. Yet another is found at the boundaries of segmental duplications and may actually induce that process [188,189].

A host of mechanisms have been identified that transcend Mendelian heritability and that account for the diversity and robustness of evolution. Doubtless others will be uncovered in the future. Genomic transformations resulting in alterations from normal gene copy number are only one of many, but they happen to be relevant to the issues at hand: the diversity of the neurodevelopmental disorders and the unique status of autism and schizophrenia as disorders of social brain. They are not the driver of primate evolution, but they have participated in that event by virtue of the variability/adaptability they confer on the genome. So also other potential drivers of primate evolution should share this characteristic namely, flexibility and efficiency in generating phenotypic variations upon which selection may operate. It is this capacity, to expand the genome to generate heritable, selectable phenotypic variation, that confers "evolvability”, or evolutionary adaptability.

\section{The HHLRS Problem}

For such thinking to win credit as a theory it must be conducive to understanding events beyond its component premises: that genomic rearrangement is a process conducive to rapid evolutionary change and substantial inter-individual re-arrangement; that the process has been more robust during primate > hominid evolution; and that its effects are pertinent to the development of socialization, intelligence and language. The first line of support comes from the association between CNVs and neurodevelopmental disorders, all of which have an impact, to a variable degree, on social relating, cognition and communication. The second is the diversity with which duplications and deletions are manifest, pathologically, and how that is concordant with the clinical, genetic and neuropathological diversity of the neurodevelopmental disorders. There is one more: the HHLRS problem. That is the puzzling fact that autism and schizophrenia are highly heritable but are also associated with low reproductive success. Theoretically, they ought to have gone extinct a long time ago. But they persist. Why?

Natural selection posits that a trait, or its underlying genes, has to confer selective advantage in order to sur- 
vive. A genetic disorder, therefore, will only persist if the genes related to the disorder 1) convey advantages in terms of survival or reproduction (genetic polymorphism) or 2) are linked to other genes that have an advantage (pleiotropy) [190,191]. One assumes, therefore, that there is some trait embedded in the autistic (or schizophrenic) genome that is advantageous to individuals who do not express the full phenotype. These ideas have been ardently pursued by students of autism and schizophrenia, but in neither case have they been able to identify what that trait may be.

With respect to autism, the occurrence of autistic styles of thinking in the first degree relatives of autistic individuals suggests traits like hyper-systematizing, preference for visuo-spatial relationships and detail-focused processing are adaptive, not only for individuals, but as we learned from the accomplishments of scientists and artists with autistic traits, for the distributed intelligence of society. If autism were a single-gene disorder, this observation would suggest heterozygote advantage. Since autism is a polygenic disorder, it suggests a Gaussian model, with traits for autistic thinking normally distributed in the population, but at the tail end of the curve the hyper-systematizers cluster, and beyond a certain threshold of expression lie the autists. An alternative view is a "cliff-edge" distribution; as genes or traits accumulate, they confer increasing advantage, but beyond a certain point, the edge of the cliff, there is a dramatic fall-off in fitness [192].

On the other hand, in the case of autism there is ample evidence of heterozygote disadvantage: high rates of language-based learning disability are found in non-autistic monozygotic co-twins (Folstein and Rutter, 1977) and there are high rates of social and communication deficits and stereotyped-repetitive behaviors in parents, aunts and uncles, and grandparents of autistic individuals [193]. Further, the parents of more than one autistic child have higher rates of particular personality characteristics (rigidity, aloofness, hypersensitivity to criticism, and anxiousness), speech and pragmatic language deficits, and more limited friendships [194]. Such qualities are unlikely to confer reproductive advantage.

With respect to schizophrenia, a common answer has also been that the schizophrenic genotype is subject to some kind of balancing selection: the benefits thus conveyed have to outbalance the destructive consequences of the disease itself [195]. In this vein, many authors have suggested that associated traits or underlying genes are advantageous; these, they say, are illustrated by the unique characteristics of psychotic individuals, that were perhaps more valued in ancestral times; or by the more general characteristics of their relatives who carried a smaller burden of the schizo genotype. They have proposed that psychotic individuals may have been charis- matic leaders or shamans [196], for example, or that their lower threshold for threat perception was useful in a time when life was nasty, brutish and short [197]. The relatives of schizophrenic individuals had increased fertility [198], more resistance to disease [199,200] or artistic creativity [201]. Schizophrenia, a single gene disorder it was proposed, was the price humanity had to pay for the gift of language [202]. Speculations of this kind are based on the assumption that the basis of psychosis is to be found in phenotypic variations, something that natural selection can select without a microscope. Their signal lack of success belies the assumption [203-206].

Explanations for the HHLRS problem have therefore been sought on the microscopic level. These have been more fruitful. For example, the cliff-edged fitness model was proposed to explain the persistence of schizophrenia by virtue of a link to synaptic pruning. Pruning, the selective elimination of weak neuronal connections, is a normal developmental process that occurs predominantly throughout childhood and adolescence. The elimination of little-used synapses improves mental efficiency; however, excessive reduction of synaptic connectivity (overpruning) may result in spontaneous and autonomous cerebral activity, causing hallucinations and other positive symptoms $[207,208]$.

Burns proposed a model based on genetic pleiomorphism: that the genes for schizophrenia were associated with genes regulating the development of complex cortical connectivity, especially with respect to the social brain. Because these regulatory genes were advantageous during hominid evolution, then the genes for the disorder would persist by virtue of their association with the adaptive genes [209]. His theory proposed a series of "trade-offs" between brain growth, complex cerebral interconnectivity and specialized neural circuits to regulate social cognition on the one hand and the anatomical constraints on fetal brain size. The solution was the expanded function of heterochronic genes that allowed brain maturation to occur over a long span of time.

This meant that the human brain, with its complex and recently evolved circuitry, became increasingly susceptible to complex gene interactions and/or genetic insults. This susceptibility was the trade-off for the advantages gained in social cognition [210].

A second trade-off occurred when genetic changes in some individuals resulted in aberrant connectivity in cortical circuits,

If the genes for schizophrenia were in some way intimately associated with genes regulating the development of complex cortical connectivity, and if these regulatory genes were advantageous during hominid evolution, then the genes for the disorder would persist by virtue of their association with the 
adaptive genes. Thus, schizophrenia would represent a trade-off in the evolution of the highly organized brain of modern Homo sapiens (p. 832).

Burn's theory emphasizes social brain evolution as the setting event and cortical connectivity as the neural substrate for the inter-individual variation and there is ample evidence for both contentions in schizophrenia, autism and other neurodevelopmental disorders. However, the essence of the theory remains pleiotropy, that is, that genes predisposing to schizophrenia are linked to the activity of regulatory genes which exercise a beneficial effect, as if they were genomic hitch-hikers. A contrasting view is polygenetic mutation-selection balance, which begins with the premise that predisposition to mental disorder has no selection advantage. Rather, inheritance of mental disorder is fueled by deleterious mutations, rare at individual loci but ubiquitous in genomes. Since more than half of all human protein-coding genes are expressed in brain tissue neural systems capture a large amount of mutational variation. This is consistent with the prevailing assumption that neural systems supporting mental processes and behavior are under polygenetic control. The mutations in question necessarily include genomic transformations like CNV's, which are under strong negative selection pressure and persist, as a rule, for only a few generations and which are continually replenished by virtue of high mutation rates [211,212].

Polygenic mutation selection balance is a likely evolutionary explanation for the maintenance of genetic variation for psychiatric disorders with low reproductive success. It explains how fitness-reducing genetic variation is maintained in the population; harmful transformations are under negative selection but variation persists because the removal of alleles is balanced by the occurrence of new transformations in the population [213]. Harmful mutations are removed from the gene pool at a rate proportional to their effect on fitness. Yet, novel mutations occur all the time [214-218]. It is common to say that the neurodevelopmental disorders are polygenic, referring to the concomitant but diverse actions of multiple genes of small effect. It may be more precise to refer to them as "polymutational”.

Evolution of the modern human brain seems to have arisen during the cultivation of unstable regions in the genome that were conducive to a high degree of interindividual and inter-generational variation. Because the impact of genetic rearrangement has been most notable during human evolution, the phenotypic variations that result are most likely to occur in gene loci that mediate functions that are uniquely human. Thus, our genome is disposed to generate a high degree of variation in the neural substrates that govern the social brain; a partial list would include neuronogenesis and neuronal migration, the growth of axons and dendritic sprouting, synaptoge- nesis and synaptic pruning, the timing at which such events occur and their resilience in the face of untoward environmental circumstances. The consequence of even small aberrations in one or more of these processes-the "watershed" model [219] —is most likely to be manifest in the functions of the social brain; a partial list to include, self-referential processing, perspective taking and the dual components of empathy. Also language, including phonological processing, which comprises the ability to decode sensory data with astonishing speed and facility; semantics and syntax, which involve the manipulation of abstractions; and pragmatics, which involves the second operation of the social brain. Also, intelligence, which involves, among other things, the fast and efficient processing of perceptual data in the service of comprehension and goal-directed behavior. The extraordinary fine motor dexterity of the human being should also be included in the list. The trade-off is that a dynamic genome can rearrange itself in untoward ways, and when it does, the consequences are felt in one or more of the functions listed above. The occurrence of neurodevelopmental disorders, therefore, ranging from the learning disabilities and ADD to autism and schizophrenia, are epiphenomenal to a genome that is unstable and mutable. The selective advantage of such a genome is the runaway evolution of positive prosocial and intellective traits.

In autism and schizophrenia, theories have posited a "core" dysfunction in social brain [220-223], in communication [224-226] and cognition [227,228]. Such theories have suffered for concentrating on one particular component of human brain evolution, while, in fact, the three components co-evolved and continue to operate in concert. Nor can a core dysfunction account for the heterogeneity of the patient populations. If there is a core to the pathology that emerges in autism and schizophrenia, it is at the genomic level, and is probably related to the unique evolvability of the human genome. Genetic transformation as an agent of evolvability is necessarily associated with untoward consequences. Just as point mutations may have deleterious effects, so do genomic transformations. The neurodevelopmental disorders, therefore, are the consequence of evolvability.

\section{Is It a Theory?}

If this argument is a theory, it should make additional predictions that can be tested. For example, one might predict that the search for autism or schizophrenia genes will continue to identify multiple genes of small effect. The genetic basis for the disorders, however, will be found in the mechanisms that promote genomic transformation, or the identification of regions of particular instability. Both conditions are highly heritable, but many sporadic cases arise; therefore, some members of the human population may be more prone to sporadic dis- 
eases than others, depending on the structural variants in their genome [229,230].

Since schizophrenia and autism have in common prominent effects on social relating, cognition and communication, the multiple genes associated with those conditions should have at least a degree of overlap. This appears to be the case [231]. But since they are very different conditions in so many ways, we should expect to discover essential differences, not only in the genes but also in the mechanisms of genetic transformation that occur and/or the size and location of unstable regions in the genome.

Current research in schizophrenia and also in autism has addressed the issue of endophenotypes, that is, a phenotypic trait that underlies the condition and that also occurs in first-degree relatives who are not afflicted but not in normal controls. The problem with this line of research thus far is that many of the characteristics proposed as endophenotypes are also discovered in other neuropsychiatric conditions that are not schizophrenia. The prediction is that this will continue to be the case. CNVs, after all, are endogenotypes, but the CNV's associated with schizophrenia are met with also in family members with diverse conditions [232].

\section{Acknowledgments/Financial Support}

Financial support from NC Neuropsychiatry Attention \& Memory Centers. Dr. Gualtieri is the founder/developer of ATONC, a freely available library of computerized tests at www.atonc.com.

\section{REFERENCES}

[1] M. Kirschner and J. Gerhart, "Evolvability,” Proceedings of the National Academy of Sciencesof the United States of America, Vol. 95, No. 15, 1998, pp. 8420-8427. http://dx.doi.org/10.1073/pnas.95.15.8420

[2] A. G. Jones, S. J. Arnold and R. Bürger, "The Mutation Matrix and the Evolution of Evolvability," Evolution: International Journal of Organic Evolution, Vol. 61, No. 4, 2007, pp. 727-745.

http://dx.doi.org/10.1111/j.1558-5646.2007.00071.x

[3] C. A. Ross, R. L. Margolis, S. A. J. Reading, M. Pletnikov and J. T. Coyle, "Neurobiology of Schizophrenia," Neuron, Vol. 52, No. 1, 2006, pp. 139-153.

http://dx.doi.org/10.1016/j.neuron.2006.09.015

[4] A. Lieberman, "Is Schizophrenia a Neurodegenerative Disorder? A Clinical and Neurobiological Perspective," Biological Psychiatry, Vol. 46, No. 6, 1999, pp. 729-739. http://dx.doi.org/10.1016/S0006-3223(99)00147-X

[5] S. B. Powell, "Models of Neurodevelopmental Abnormalities in Schizophrenia," Current Topics in Behavioral Neurosciences, Vol. 4, 2010, pp. 435-481. http://dx.doi.org/10.1007/7854 201057

[6] J. L. Rapoport, A. M. Addington, S. Frangou and M. R. C.
Psych, "The Neurodevelopmental Model of Schizophrenia: Update 2005,” Molecular Psychiatry, Vol. 10, No. 5, 2005, pp. 434-449. http://dx.doi.org/10.1038/sj.mp.4001642

[7] S. H. Fatemi and T. D. Folsom, "The Neurodevelopmental Hypothesis of Schizophrenia, Revisited," Schizophrenia Bulletin, Vol. 35, No. 3, 2009, pp. 528-548.

http://dx.doi.org/10.1093/schbul/sbn187

[8] J. R. Lupski, “Genomic Disorders: Structural Features of the Genome Can Lead to DNA Rearrangements and Human Disease Traits," Trends in Genetics: TIG, Vol. 14, No. 10, 1998, pp. 417-422. http://dx.doi.org/10.1016/S0168-9525(98)01555-8

[9] A. S. Kondrashov, "Direct Estimates of Human per Nucleotide Mutation Rates at 20 Loci Causing Mendelian Diseases,” Human Mutation, Vol. 21, No. 1, 2003, pp. 12-27. http://dx.doi.org/10.1002/humu.10147

[10] P. Stankiewicz and J. R. Lupski, "Genome Architecture, Rearrangements and Genomic Disorders,” Trends in Genetics: TIG, Vol. 18, No. 2, 2002, pp. 74-82. http://dx.doi.org/10.1016/S0168-9525(02)02592-1

[11] J. A. Lee and J. R. Lupski, “Genomic Rearrangements and Gene Copy-Number Alterations as a Cause of Nervous System Disorders,” Neuron, Vol. 52, No. 1, 2006, pp. 103-121. http://dx.doi.org/10.1016/j.neuron.2006.09.027

[12] J. R. Lupski, "Genomic Rearrangements and Sporadic Disease,” Nature Genetics, Vol. 39, No. 7, 2007, pp. S43S47. http://dx.doi.org/10.1038/ng2084

[13] L. G. Shaffer, et al., "The Discovery of Microdeletion Syndromes in the Post-Genomic Era: Review of the Methodology and Characterization of a New 1q41q42 Microdeletion Syndrome," Genetics in Medicine: Official Journal of the American College of Medical Genetics, Vol. 9, No. 9, 2007, pp. 607-616.

[14] C. M. B. Carvalho, F. Zhang and J. R. Lupski, "Genomic Disorders: A Window into Human Gene and Genome Evolution," Proceedings of the National Academy of Sciences of the United States of America, Vol. 107, Supplement 1, 2010, pp. 1765-1771. http://dx.doi.org/10.1073/pnas.0906222107

[15] J. R. Lupski, R. M. de Oca-Luna, S. Slaugenhaupt, P. T. Liu, V. Guzzetta, B. J. Trask, O. Saucedo-Cardenas, D. F. Barker, J. M. Killian, C. A. Garcia, A. Chakravarti and P. I. Patel, "DNA Duplication Associated with Charcot-MarieTooth Disease Type 1A,” Cell, Vol. 66, No. 2, 1991, pp. 219-232. http://dx.doi.org/10.1016/0092-8674(91)90613-4

[16] E. M. Morrow, "Genomic Copy Number Variation in Disorders of Cognitive Development," Journal of the American Academy of Child and Adolescent Psychiatry, Vol. 49, No. 11, 2010, pp. 1091-1104. http://dx.doi.org/10.1016/j.jaac.2010.08.009

[17] J. R. Lupski, “Genomic Disorders: Structural Features of the Genome Can Lead to DNA Rearrangements and Human Disease Traits,” Trends in Genetics, Vol. 14, No. 10, 1998, pp. 417-422.

[18] E. E. Eichler, N. Archidiacono and M. Rocchi, "CAGGG Repeats and the Pericentromeric Duplication of the Hominoid Genome,” Genome Research, Vol. 9, No. 11, 1999, 
pp. 1048-1058. http://dx.doi.org/10.1101/gr.9.11.1048

[19] J. A. Lee and J. R. Lupski, "Genomic Rearrangements and Gene Copy-Number Alterations as a Cause of Nervous System Disorders," Neuron, Vol. 52, No. 1, 2006, pp. 103-121.

[20] R. Redon, et al., "Global Variation in Copy Number in the Human Genome,” Nature, Vol. 444, No. 7118, 2006, pp. 444-454. http://dx.doi.org/10.1038/nature05329

[21] L. Feuk, A. R. Carson and S. W. Scherer, "Structural Variation in the Human Genome," Nature Reviews. Genetics, Vol. 7, No. 2, 2006, pp. 85-97. http://dx.doi.org/10.1038/nrg1767

[22] S. Levy, G. Sutton, P. C. Ng, et al., "The Diploid Genome Sequence of an Individual Human,” PLoS Biology, Vol. 5, No. 10, 2007, Article ID: e254. http://dx.doi.org/10.1371/journal.pbio.0050254

[23] D. A. Wheeler, et al., "The Complete Genome of an Individual by Massively Parallel DNA Sequencing," Nature, Vol. 452, No. 7189, 2008, pp. 872-876. http://dx.doi.org/10.1038/nature06884

[24] M. E. Hurles, E. T. Dermitzakis and C. Tyler-Smith, "The Functional Impact of Structural Variation in Humans," Trends in Genetics: TIG, Vol. 24, No. 5, 2008, pp. 238245. http://dx.doi.org/10.1016/j.tig.2008.03.001

[25] B. E. Stranger, et al., "Relative Impact of Nucleotide and Copy Number Variation on Gene Expression Phenotypes," Science, Vol. 315, No. 5813, 2007, pp. 848-853. http://dx.doi.org/10.1126/science.1136678

[26] J. A. Buchanan and S. W. Scherer, "Contemplating Effects of Genomic Structural Variation," Genetics in Medicine: Official Journal of the American College of Medical Genetics, Vol. 10, No. 9, 2008, pp. 639-647.

[27] D. F. Conrad, et al., "Origins and Functional Impact of Copy Number Variation in the Human Genome,” Nature, Vol. 464, No. 7289, 2010, pp. 704-712. http://dx.doi.org/10.1038/nature08516

[28] J. A. Bailey and E. E. Eichler, "Primate Segmental Duplications: Crucibles of Evolution, Diversity and Disease," Nature Reviews. Genetics, Vol. 7, No. 7, 2006, pp. 552564. http://dx.doi.org/10.1038/nrg1895

[29] M. E. Feder, "Evolvability of Physiological and Biochemical Traits: Evolutionary Mechanisms Including and beyond Single-Nucleotide Mutation,” Journal of Experimental Biology, Vol. 210, No. 9, 2007, pp. 1653-1660. http://dx.doi.org/10.1242/jeb.02725

[30] S. Ohno, U. Wolf and N. B. Atkin, "Evolution from Fish to Mammals by Gene Duplication," Hereditas, Vol. 59, No. 1, 1968, pp. 169-187. http://dx.doi.org/10.1111/j.1601-5223.1968.tb02169.x

[31] K. Inoue, et al., “The 1.4-Mb CMT1A Duplication/HNPP Deletion Genomic Region Reveals Unique Genome Architectural Features and Provides Insights into the Recent Evolution of New Genes," Genome Research, Vol. 11, No. 6, 2001, pp. 1018-1033. http://dx.doi.org/10.1101/gr.180401

[32] C. M. B. Carvalho, F. Zhang and J. R. Lupski, "Genomic Disorders: A Window into Human Gene and Genome Evolution," Proceedings of the National Academy of Sci- ences of the United States of America, Vol.107, Supplement 1, 2010.

[33] E. H. Cook Jr. and S. W. Scherer, “Copy-Number Variations Associated with Neuropsychiatric Conditions," Nature, Vol. 455, No. 7215, 2008, pp. 919-923. http://dx.doi.org/10.1038/nature07458

[34] J. Sebat, D. L. Levyand S. E. McCarthy, "Rare Structural Variants in Schizophrenia: One Disorder, Multiple Mutations; One Mutation, Multiple Disorders," Trends in Genetics, Vol. 25, No. 12, 2009, pp. 528-535. http://dx.doi.org/10.1016/j.tig.2009.10.004

[35] E. H. Cook Jr. and S. W. Scherer, "Copy-Number Variations Associated with Neuropsychiatric Conditions," Nature, Vol. 455, No. 7215, 2008, pp. 919-923.

[36] M. L. Jacquemont, et al., “Array-Based Comparative Genomic Hybridisation Identifies High Frequency of Cryptic Chromosomal Rearrangements in Patients with Syndromic Autism Spectrum Disorders," Journal of Medical Genetics, Vol. 43, No. 11, 2006, pp. 843-849. http://dx.doi.org/10.1136/jmg.2006.043166

[37] J. E. Chubb, N. J. Bradshaw, D. C. Soares, D. J. Porteous and J. K. Millar, "The DISC Locus in Psychiatric Illness," Molecular Psychiatry, Vol. 13, No. 1, 2008, pp. 36-64. http://dx.doi.org/10.1038/sj.mp.4002106

[38] J. Sebat, et al., "Strong Association of de Novo Copy Number Mutations with Autism," Science, Vol. 316, No. 5823, 2007, pp. 445-449. http://dx.doi.org/10.1126/science.1138659

[39] D. Pinto, et al., "Functional Impact of Global Rare Copy Number Variation in Autism Spectrum Disorder," Nature, Vol. 466, No. 7304, 2010, pp. 368-372. http://dx.doi.org/10.1038/nature09146

[40] International Schizophrenia Consortium, "Rare Chromosomal Deletions and Duplications Increase Risk of Schizophrenia,” Nature, Vol. 455, No. 7210, 2008, pp. 237241. http://dx.doi.org/10.1038/nature07239

[41] O. Ousley, K. Rockers, M. L. Dell, K. Coleman and J. F. Cubells, "A Review of Neurocognitive and Behavioral Profiles Associated with 22q11 Deletion Syndrome: Implications for Clinical Evaluation and Treatment," Current Psychiatry Reports, Vol. 9, No. 2, 2007, pp. 148-158. http://dx.doi.org/10.1007/s11920-007-0085-8

[42] D. Gothelf, et al., "Genetic, Developmental, and Physical Factors Associated with Attention Deficit Hyperactivity Disorder in Patients with Velocardiofacial Syndrome," American Journal of Medical Genetics. Part B: Neuropsychiatric Genetics: The Official Publication of the International Society of Psychiatric Genetics, Vol. 126B, No. 1, 2004, pp. 116-121. http://dx.doi.org/10.1002/ajmg.b.20144

[43] T. Walsh, et al., "Rare Structural Variants Disrupt Multiple Genes in Neurodevelopmental Pathways in Schizophrenia,” Science, Vol. 320, No. 5875, 2008, pp. 539-543. http://dx.doi.org/10.1126/science.1155174

[44] H. Stefansson, et al., "Large Recurrent Microdeletions Associated with Schizophrenia,” Nature, Vol. 455, No. 7210, 2008, pp. 232-236. http://dx.doi.org/10.1038/nature07229

[45] N. Brunetti-Pierri, et al., "Recurrent Reciprocal 1q21.1 
Deletions and Duplications Associated with Microcephaly or Macrocephaly and Developmental and Behavioral Abnormalities," Nature Genetics, Vol. 40, No. 12, 2008, pp. 1466-1471. http://dx.doi.org/10.1038/ng.279

[46] H. C. Mefford, et al., "Recurrent Rearrangements of Chromosome 1q21.1 and Variable Pediatric Phenotypes," The New England Journal of Medicine, Vol. 359, No. 16, 2008, pp. 1685-1699. http://dx.doi.org/10.1056/NEJMoa0805384

[47] I. Helbig, et al., "15q13.3 Microdeletions Increase Risk of Idiopathic Generalized Epilepsy,” Nature Genetics, Vol. 41, No. 2, 2009, pp. 160-162. http://dx.doi.org/10.1038/ng.292

[48] L. M. Dibbens, et al., "Familial and Sporadic 15q13.3 Microdeletions in Idiopathic Generalized Epilepsy: Precedent for Disorders with Complex Inheritance,” Human Molecular Genetics, Vol. 18, No. 19, 2009, pp. 36263631. http://dx.doi.org/10.1093/hmg/ddp311

[49] A. J. Sharp, et al., "Discovery of Previously Unidentified Genomic Disorders from the Duplication Architecture of the Human Genome," Nature Genetics, Vol. 38, No. 9, 2006, pp. 1038-1042. http://dx.doi.org/10.1038/ng1862

[50] L. A. Weiss, et al., "Association between Microdeletion and Microduplication at 16p11.2 and Autism," The New England Journal of Medicine, Vol. 358, No. 7, 2008, pp. 667-675. http://dx.doi.org/10.1056/NEJMoa075974

[51] T. Walsh, et al., "Rare Structural Variants Disrupt Multiple Genes in Neurodevelopmental Pathways in Schizophrenia,” Science, Vol. 320, No. 5875, 2008, pp. 539543.

[52] M. Doornbos, et al., "Nine Patients with a Microdeletion 15q11.2 between Breakpoints 1 and 2 of the Prader-Willi Critical Region, Possibly Associated with Behavioural Disturbances," European Journal of Medical Genetics, Vol. 52, No. 2-3, 2009, pp. 108-115. http://dx.doi.org/10.1016/j.ejmg.2009.03.010

[53] S. Ohno, U. Wolf and N. B. Atkin, "Evolution from Fish to Mammals by Gene Duplication," Hereditas, Vol. 59, No. 1, 1968, pp. 167-187.

[54] J. Sebat, et al., "Large-Scale Copy Number Polymorphism in the Human Genome,” Science, Vol. 305, No. 5683, 2004, pp. 525-528. http://dx.doi.org/10.1126/science.1098918

[55] E. M. Morrow, "Genomic Copy Number Variation in Disorders of Cognitive Development," Journal of the American Academy of Child and Adolescent Psychiatry, Vol. 49, No. 11, 2010, pp. 1091-1104.

[56] A. J. Iafrate, L. Feuk, M. N. Rivera, M. L. Listewnik, P. K. Donahoe, Y. Qi, S. W. Scherer and C. Lee, "Detection of Large-Scale Variation in the Human Genome," Nature Genetics, Vol. 36, No. 9, 2004, pp. 949-951. http://dx.doi.org/10.1038/ng1416

[57] E. M. Morrow, "Genomic Copy Number Variation in Disorders of Cognitive Development," Journal of the American Academy of Child and Adolescent Psychiatry, Vol. 49, No. 11, 2010, pp. 1091-1104.

[58] J. R. Lupski, "Genomic Rearrangements and Sporadic Disease,” Nature Genetics, Vol. 39, 2007, pp. S43-S47.

[59] J. R. Lupski, "Genomic Rearrangements and Sporadic
Disease,” Nature Genetics, Vol. 39, 2007, pp. S43-S47.

[60] T. Marques-Bonet and E. E. Eichler, "The Evolution of Human Segmental Duplications and the Core Duplicon Hypothesis," Cold Spring Harbor Symposia on Quantitative Biology, Vol. 74, 2009, pp. 355-362. http://dx.doi.org/10.1101/sqb.2009.74.011

[61] S. Ohno, U. Wolf and N. B. Atkin, "Evolution from Fish to Mammals by Gene Duplication," Hereditas, Vol. 59, No. 1, 1968, pp. 167-187.

[62] J. M. Chen, D. N. Cooper, C. Férec, H. Kehrer-Sawatzkif and G. P. Patrinos, "Genomic Rearrangements in Inherited Disease and Cancer," Seminars in Cancer Biology, Vol. 20, No. 4, 2010, pp. 222-233. http://dx.doi.org/10.1016/j.semcancer.2010.05.007

[63] J. Sebat, et al., "Large-Scale Copy Number Polymorphism in the Human Genome,” Science, Vol. 305, No. 5683, 2004, pp. 525-528.

[64] N. Burnashev and A. Rozov, "Genomic Control of Receptor Function,” Cellular and Molecular Life Sciences: CMLS, Vol. 57, No. 11, 2000, pp. 1499-1507. http://dx.doi.org/10.1007/PL00000634

[65] J. J. Yunis and O. Prakash, "The Origin of Man: A Chromosomal Pictorial Legacy,” Science, Vol. 215, No. 4539, 1982, pp. 1525-1530. http://dx.doi.org/10.1126/science.7063861

[66] D. E. Wildman, M. Uddin, G. Z. Liu, L. I. Grossman and M. Goodman, "Implications of Natural Selection in Shaping 99.4\% Nonsynonymous DNA Identity between Humans and Chimpanzees: Enlarging Genus Homo,” Proceedings of the National Academy of Sciences of the United States of America, Vol. 100, No. 12, 2003, pp. 7181-7188. http://dx.doi.org/10.1073/pnas.1232172100

[67] T. Marques-Bonet, S. Girirajan and E. E. Eichler, "The Origins and Impact of Primate Segmental Duplications," Trends in Genetics: TIG, Vol. 25, No. 10, 2009, pp. 443454. http://dx.doi.org/10.1016/j.tig.2009.08.002

[68] J. J. Yunis and O. Prakash, "The Origin of Man: A Chromosomal Pictorial Legacy,” Science, Vol. 215, No. 4539, 1982, pp. 1525-1530.

[69] A. Jauch, J. Wienberg, R. Stanyon, N. Arnold, S. Tofanelli, T. Ishida and T. Cremer, "Reconstruction of Genomic Rearrangements in Great Apes and Gibbons by Chromosome Painting.," Proceedings of the National Academy of Sciences of the United States of America, Vol. 89, No. 18, 1992, pp. 8611-8615.

http://dx.doi.org/10.1073/pnas.89.18.8611

[70] J. L. Nahon, "Birth of 'Human-Specific' Genes during Primate Evolution,” Genetica, Vol. 118, No. 2-3, 2003, pp. 193-208. http://dx.doi.org/10.1023/A:1024157714736

[71] M. Kirschner and J. Gerhart, “Evolvability,” Proceedings of the National Academy of Sciences of the United States of America, Vol. 95, No. 15, 1998, pp. 8420-8427.

[72] K. Inoue, et al., "The 1.4-Mb CMT1A Duplication/HNPP Deletion Genomic Region Reveals Unique Genome Architectural Features and Provides Insights into the Recent Evolution of New Genes," Genome Research, Vol. 11, No. 6, 2001, pp. 1018-1033.

[73] K. Inoue and J. R. Lupski, "Molecular Mechanisms for 
Genomic Disorders,” Annual Review of Genomics and Human Genetics, Vol. 3, 2002, pp. 199-242. http://dx.doi.org/10.1146/annurev.genom.3.032802.12002 $\underline{3}$

[74] R. V. Samonte and E. E. Eichler, "Segmental Duplications and the Evolution of the Primate Genome," Nature Reviews. Genetics, Vol. 3, No. 1, 2002, pp. 65-72. http://dx.doi.org/10.1038/nrg705

[75] P. Stankiewicz and J. R. Lupski, "Genome Architecture, Rearrangements and Genomic Disorders,” Trends in Genetics, Vol. 18, No. 2, 2002, pp. 74-82.

[76] A. Clark, "Being There: Bringing Brain, Body and World Together,” MIT Press, Cambridge, 1997.

[77] S. Pinker, "The Cognitive Niche: Coevolution of Intelligence, Sociality, and Language," Proceedings of the National Academy of Sciences of the United States of America, Vol. 107, Suppl. 2, 2010, pp. 8993-8999. http://dx.doi.org/10.1073/pnas.0914630107

[78] R. I. M. Dunbar, "The Social Brain Hypothesis,” Brain, Vol. 9, 1998, p. 10.

[79] L. C. Aiello and P. Wheeler, "The Expensive Tissue Hypothesis. the Brain and the Digestive System in Human Evolution," Current Anthropology, Vol. 36, No. 2, 1995, pp. 199-221. http://dx.doi.org/10.1086/204350

[80] E. Fehr and U. Fischbacher, "The Nature of Human Altruism,” Nature, Vol. 425, No. 6960, 2003, pp. 785-791. http://dx.doi.org/10.1038/nature02043

[81] L. Willerman, R. Schultz, J. N. Rutledge and E. D. Bigler, "In Vivo Brain Size and Intelligence," Intelligence, Vol. 15, No. 2, 1991, pp. 223-228. http://dx.doi.org/10.1016/0160-2896(91)90031-8

[82] P. Lindenfors, C. L. Nunn and R. A. Barton, "Primate Brain Architecture and Selection in Relation to Sex," BMC Biology, Vol. 5, 2007, p. 20. http://dx.doi.org/10.1186/1741-7007-5-20

[83] R. I. M. Dunbar and S. Shultz, "Evolution in the Social Brain,” Science, Vol. 317, No. 5843, 2007, pp. 1344-1347. http://dx.doi.org/10.1126/science.1145463

[84] M. R. A. Chance and A. P. Mead, "Social Behaviour and Primate Evolution," Symposia of the Society for Experimental Biology, Vol. 7, 1953, pp. 395-439.

[85] R. I. M. Dunbar and S. Shultz, "Evolution in the Social Brain,” Science, Vol. 317, No. 5843, 2007, pp. 13441347.

[86] R. I. M. Dunbar and S. Shultz, "Evolution in the Social Brain,” Science, Vol. 317, No. 5843, 2007, pp. 13441347.

[87] S. Shultz and R. I. M. Dunbar, "The Evolution of the Social Brain: Anthropoid Primates Contrast with Other Vertebrates," Proceedings of the Royal Society B: Biological Sciences, Vol. 274, No. 1624, 2007, pp. 2429-2436. http://dx.doi.org/10.1098/rspb.2007.0693

[88] L. Barrett and P. Henzi, “The Social Nature of Primate Cognition,” Proceedings of the Royal Society B: Biological Sciences, Vol. 272, No. 1575, 2005, pp. 1865-1875. http://dx.doi.org/10.1098/rspb.2005.3200

[89] R. I. M. Dunbar, “The Social Brain Hypothesis,” Evolu- tionary Anthropology: Issues, News, and Reviews, Vol. 6, No. 5, 1998, pp 178-190.

[90] L. Brothers, “The Social Brain: A Project for Integrating Primate Behaviour and Neurophysiology in a New Domain,” In: Foundations in Social Neuroscience, MIT Press, Cambridge, 2002, pp. 367-389.

[91] R. W. Byrne and N. Corp, "Neocortex Size Predicts Deception Rate in Primates," Proceedings of the Royal Society B: Biological Sciences, Vol. 271, No. 1549, 2004, pp. 1693-1699. http://dx.doi.org/10.1098/rspb.2004.2780

[92] A. Whiten and R. W. Byrne, "Machiavellian Intelligence II: Extensions and Evaluations,” Cambridge University Press, Cambridge, 1997.

[93] E. Fehr and U. Fischbacher, "The Nature of Human Altruism,” Nature, Vol. 425, 2003, pp. 785-791.

[94] E. Fehr and S. Gächter, "Altruistic Punishment in Humans,” Nature, Vol. 415, No. 6868, 2002, pp. 137-140. http://dx.doi.org/10.1038/415137a

[95] C. T. Gualtieri, "Brain Injury and Mental Retardation: Neuropsychiatry and Psychopharmacology,” Lippincott Williams and Wilkins, Philadelphia, 2002.

[96] K. Rosenberg and W. Trevathan, "Bipedalism and Human Birth: The Obstetrical Dilemma Revisited,” Evolutionary Anthropology: Issues, News, and Reviews, Vol. 4, No. 5, 1995, pp. 161-168. http://dx.doi.org/10.1002/evan.1360040506

[97] S. L. Washburn, “Tools and Human Evolution,” Scientific American, Vol. 203, No., 1960, pp. 63-75.

[98] H. M. Dunsworth, et al., "Metabolic Hypothesis for Human Altriciality," Proceedings of the National Academy of Sciences of the United States of America, Vol. 109, No. 38, 2012, pp. 15212-15216. http://dx.doi.org/10.1073/pnas.1205282109

[99] P. Lindenfors, C. L. Nunn and R. A. Barton, "Primate Brain Architecture and Selection in Relation to Sex," BMC Biology, Vol. 5, 2007, p. 20.

[100] E. B. Keverne, F. L. Martel and C. M. Nevison, "Primate Brain Evolution: Genetic and Functional Considerations," Proceedings of the Royal Society B: Biological Sciences, Vol. 263, No. 1371, 1996, pp. 689-696. http://dx.doi.org/10.1098/rspb.1996.0103

[101] S. Stanley, "Children of the Ice Age," Freeman, New York, 1998.

[102] S. Pinker, "The Cognitive Niche: Coevolution of Intelligence, Sociality, and Language," Proceedings of the National Academy of Sciences of the United States of America, Vol. 107, No. 2, 2010, pp. 8993-8999.

[103] R. A. Fisher, "The Genetical Theory of Natural Selection,” Clarendon Press, Oxford, 1930.

[104] R. Lande, "Models of Speciation by Sexual Selection on Polygenic Traits," Proceedings of the National Academy of Sciences of the United States of America, Vol. 78, No. 6, 1981, pp. 3721-3725. http://dx.doi.org/10.1073/pnas.78.6.3721

[105] C. Wills, “The Runaway Brain: The Evolution of Human Uniqueness,” Basic Books, New York, 1993. 
[106] G. Miller, "The Mating Mind: How Sexual Choice Shaped the Evolution of Human Nature," Anchor, New York, 2001.

[107] J. H. Kaas, "The Evolution of Brains from Early Mammals to Humans," Wiley Interdisciplinary Reviews: Cognitive Science, Vol. 4, No. 1, 2013, pp. 33-45. http://dx.doi.org/10.1002/wcs.1206

[108] E. L. Thorndike, “Intelligence and Its Uses,” Harper's Magazine, Vol. 140, 1920, pp. 227-235.

[109] A. Smith, “Thoey of Moral Sentiments,” A Miller, London, 1759.

[110] M. F. Green, et al., "Social Cognition in Schizophrenia: Recommendations from the Measurement and Treatment Research to Improve Cognition in Schizophrenia New Approaches Conference,” Schizophrenia Bulletin, Vol. 31, No. 4, 2005, pp. 882-887.

http://dx.doi.org/10.1093/schbul/sbi049

[111] J. Decety and C. Lamm, "Human Empathy through the Lens of Social Neuroscience,” The Scientific World Journal, Vol. 6, 2006, pp. 1146-1163. http://dx.doi.org/10.1100/tsw.2006.221

[112] D. A. Gusnard, E. Akbudak, G. L. Shulman and M. E. Raichle, "Medial Prefrontal Cortex and Self-Referential Mental Activity: Relation to a Default Mode of Brain Function," Proceedings of the National Academy of Sciences of the United States of America, Vol. 98, No. 7, 2001, pp. 4259-4264. http://dx.doi.org/10.1073/pnas.071043098

[113] D. M. Amodio and C. D. Frith, "Meeting of Minds: The Medial Frontal Cortex and Social Cognition,” Nature Reviews Neuroscience, Vol. 7, No. 4, 2006, pp. 268-277. http://dx.doi.org/10.1038/nrn1884

[114] W. M. Kelley, C. N. Macrae, C. L. Wyland, S. Caglar, S. Inati and T. F. Heatherton, "Finding the Self? An EventRelated fMRI Study,” Journal of Cognitive Neuroscience, Vol. 14, No. 5, 2002, pp. 785-794. http://dx.doi.org/10.1162/08989290260138672

[115] C. N. Macrae, J. M. Moran, T. F. Heatherton, J. F. Banfield and W. M. Kelley, "Medial Prefrontal Activity Predicts Memory for Self,” Cerebral Cortex, Vol. 14, No. 6, 2004, pp. 647-654. http://dx.doi.org/10.1093/cercor/bhh025

[116] K. N. Ochsner, et al., "The Neural Correlates of Direct and Reflected Self-Knowledge,” NeuroImage, Vol. 28, No. 4, 2005, pp. 797-814. http://dx.doi.org/10.1016/j.neuroimage.2005.06.069

[117] R. Saxe, J. M. Moran, J. Scholz and J. Gabrieli, “Overlapping and Non-Overlapping Brain Regions for Theory of Mind and Self Reflection in Individual Subjects," Social Cognitive and Affective Neuroscience, Vol. 1, No. 3, 2006, pp. 229-234. http://dx.doi.org/10.1093/scan/nsl034

[118] S. J. Gilbert, et al., "Functional Specialization within Rostral Prefrontal Cortex (Area 10): A Meta-Analysis,” Journal of Cognitive Neuroscience, Vol. 18, No. 6, 2006, pp. 932-948. http://dx.doi.org/10.1162/jocn.2006.18.6.932

[119] D. A. Gusnard, et al., "Medial Prefrontal Cortex and Self-
Referential Mental Activity: Relation to a Default Mode of Brain Function,” Proceedings of the National Academy of Sciences of the United States of America, Vol. 98, No. 7, 2001, pp. 4259-4264.

[120] P. Ruby and J. Decety, "Effect of Subjective Perspective Taking during Simulation of Action: A PET Investigation of Agency,” Nature Neuroscience, Vol. 4, No. 5, 2001, pp. 546-550.

[121] A. E. Cavanna and M. R. Trimble, "The Precuneus: A Review of Its Functional Anatomy and Behavioural Correlates,” Brain, Vol. 129, No. 3, 2006, pp. 564-583. http://dx.doi.org/10.1093/brain/awl004

[122] K. Semendeferi, E. Armstrong, A. Schleicher, K. Zilles and G. W. Van Hoesen, "Prefrontal Cortex in Humans and Apes: A Comparative Study of Area 10," American Journal of Physical Anthropology, Vol. 114, No. 3, 2001, pp. 224-241.

http://dx.doi.org/10.1002/1096-8644(200103)114:3<224:: AID-AJPA1022>3.0.CO;2-I

[123] F. de Vignemont and T. Singer, "The Empathic Brain: How, When and Why?" Trends in Cognitive Sciences, Vol. 10, No. 10, 2006, pp. 435-441. http://dx.doi.org/10.1016/j.tics.2006.08.008

[124] R. L. Moseley, F. Pulvermüller and Y. Shtyrov, "Sensorimotor Semantics on the Spot: Brain Activity Dissociates between Conceptual Categories within 150 Ms," Scientific Reports, Vol. 3, 2013. http://dx.doi.org/10.1038/srep01928

[125] R. Adolphs, “The Neurobiology of Social Cognition,” Current Opinion in Neurobiology, Vol. 11, No. 2, 2001, pp. 231-239.

http://dx.doi.org/10.1016/S0959-4388(00)00202-6

[126] T. Allison, A. Puce and G. McCarthy, "Social Perception from Visual Cues: Role of the STS Region," Trends in Cognitive Sciences, Vol. 4, No. 7, 2000, pp. 267-278. http://dx.doi.org/10.1016/S1364-6613(00)01501-1

[127] J. V. Haxby, E. A. Hoffman and M. Gobbini, “The Distributed Human Neural System for Face Perception,” Trends in Cognitive Sciences, Vol. 4, No. 6, 2000, pp. 223-233. http://dx.doi.org/10.1016/S1364-6613(00)01482-0

[128] R. Adolphs, "Cognitive Neuroscience of Human Social Behaviour,” Nature Reviews. Neuroscience, Vol. 4, No. 3, 2003, pp. 165-178. http://dx.doi.org/10.1038/nrn1056

[129] R. Adolphs, “The Neurobiology of Social Cognition,” Current Opinion in Neurobiology, Vol. 11, 2001, PP. 231-239.

[130] R. L. Moseley, F. Pulvermüller and Y. Shtyrov, "Sensorimotor Semantics on the Spot,” Scientific Reports, Vol. 3, 2013.

[131] L. Cattaneo and G. Rizzolatti, "The Mirror Neuron System,” JAMA Neurology, Vol. 66, No. 5, 2009, pp. 557-560.

[132] B. Wicker, et al., "Both of Us Disgusted in My Insula: The Common Neural Basis of Seeing and Feeling Disgust,” Neuron, Vol. 40, No. 3, 2003, pp. 655-664. http://dx.doi.org/10.1016/S0896-6273(03)00679-2

[133] L. Carr, M. Iacoboni, M. C. Dubeau, J. C. Mazziotta and G. L. Lenzi, "Neural Mechanisms of Empathy in Humans: A Relay from Neural Systems for Imitation to Limbic Areas,” Proceedings of the National Academy of Sciences 
of the United States of America, Vol. 100, No. 9, 2003, pp. 5497-5502. http://dx.doi.org/10.1073/pnas.0935845100

[134] M. H. Grosbras and T. Paus, "Brain Networks Involved in Viewing Angry Hands or Faces,” Cerebral Cortex, Vol. 16, No. 8, 2006, pp. 1087-1096. http://dx.doi.org/10.1093/cercor/bhj050

[135] J. Decety and C. Lamm, "Human Empathy through the Lens of Social Neuroscience,” The Scientific World Journal, Vol. 6, 2006, pp. 1146-1163

[136] M. Dapretto, et al., "Understanding Emotions in Others: Mirror Neuron Dysfunction in Children with Autism Spectrum Disorders,” Nature Neuroscience, Vol. 9, No. 1, 2006, pp. 28-30. http://dx.doi.org/10.1038/nn1611.

[137] T. Perkins, M. Stokes, J. McGillivraya and R. Bittar, "Mirror Neuron Dysfunction in Autism Spectrum Disorders,” Journal of Clinical Neuroscience: Official Journal of the Neurosurgical Society of Australasia, Vol. 17, No. 10, 2010, pp. 1239-1243.

http://dx.doi.org/10.1016/j.jocn.2010.01.026

[138] L. Cattaneo and G. Rizzolatti, “The Mirror Neuron System,” JAMA Neurology, Vol. 66, No. 5, 2009, pp. 557560.

[139] B. A. Völlm, et al., "Neuronal Correlates of Theory of Mind and Empathy: A Functional Magnetic Resonance Imaging Study in a Nonverbal Task," NeuroImage, Vol. 29, No. 1, 2006, pp. 90-98.

http://dx.doi.org/10.1016/j.neuroimage.2005.07.022

[140] R. Adolphs, “The Neurobiology of Social Cognition,” Current Opinion in Neurobiology, Vol. 11, 2001, pp. 231-239.

[141] F. B. M. de Waal, "Putting the Altruism Back into Altruism: The Evolution of Empathy,” Annual Review of Psychology, Vol. 59, 2008, pp. 279-300.

http://dx.doi.org/10.1146/annurev.psych.59.103006.0936 $\underline{25}$

[142] C. Darwin, “The Descent of Man,” John Murray, London, 1871.

[143] G. P. Wagner and L. Altenberg, "Complex Adaptations and the Evolution of Evolvability," Evolution, Vol. 50, No. 3, 1996, pp. 967-976. http://dx.doi.org/10.2307/2410639

[144] M. Kirschner and J. Gerhart, "Evolvability,” Proceedings of the National Academy of Sciences of the United States of America, Vol. 95, No. 15, 1998, pp. 8420-8427.

[145] M. E. Feder, "Evolvability of Physiological and Biochemical Traits," The Journal of Experimental Biology, Vol. 210, 2007 pp. 1653-1660.

[146] C. Wills, "The Runaway Brain: The Evolution of Human Uniqueness,” Publisher, place of publication, Year of publication.

[147] M. Pigliucci, “Is Evolvability Evolvable?” Nature Reviews Genetics, Vol. 9, No. 1, 2008, pp. 75-82. http://dx.doi.org/10.1038/nrg2278

[148] W. M. Gommans, S. P. Mullen and S. Maas, "RNA Editing: A Driving Force for Adaptive Evolution?” BioEssays: News and Reviews in Molecular, Cellular and Developmental Biology, Vol. 31, No. 10, 2009, pp. 1137-1145. http://dx.doi.org/10.1002/bies.200900045
[149] M. E. Feder, "Evolvability of Physiological and Biochemical Traits,” The Journal of Experimental Biology, Vol. 210, 2007 pp. 1653-1660.

[150] C. Cañestro, H. Yokoi and J. H. Postlethwait, "Evolutionary Developmental Biology and Genomics," Nature Reviews Genetics, Vol. 8, No. 12, 2007, pp. 932-942. http://dx.doi.org/10.1038/nrg2226

[151] G. B. Muller, "Evo-Devo: Extending the Evolutionary Synthesis," Nature Reviews Genetics, Vol. 8, No. 12, 2007, pp. 943-949. http://dx.doi.org/10.1038/nrg2219

[152] N. Burnashev and A. Rozov, "Genomic Control of Receptor Function,” Cellular and Molecular Life Sciences, Vol. 57, No. 11, 2000, pp. 1499-1507.

[153] W. Enard, et al., "Intra- and Interspecific Variation in Primate Gene Expression Patterns,” Science, Vol. 296, No. 5566, 2002, pp. 340-343.

http://dx.doi.org/10.1126/science.1068996

[154] Chimpanzee Sequencing and Analysis Consortium, "Initial Sequence of the Chimpanzee Genome and Comparison with the Human Genome,” Nature, Vol. 437, No. 7055, 2005, pp. 69-87.

http://dx.doi.org/10.1038/nature04072

[155] S. Dorus, et al., "Accelerated Evolution of Nervous System Genes in the Origin of Homo Sapiens," Cell, Vol. 119, No. 7, 2004, pp. 1027-1040. http://dx.doi.org/10.1016/j.cell.2004.11.040

[156] W. M. Gommans, S. P. Mullen and S. Maas, "RNA Editing: A Driving Force for Adaptive Evolution?” BioEssays, Vol. 31, No. 10, 2009, pp. 1137-1145.

[157] K. Garber, K. T. Smith, D. Reines and S. T. Warren, "Transcription, Translation and Fragile X Syndrome," Current Opinion in Genetics \& Development, Vol. 16, No. 3, 2006, pp. 270-275. http://dx.doi.org/10.1016/j.gde.2006.04.010

[158] A. J. Verkerk, et al., "Identification of a Gene (FMR-1) Containing a CGG Repeat Coincident with a Breakpoint Cluster Region Exhibiting Length Variation in Fragile X Syndrome,” Cell, Vol. 65, No. 5, 1991, pp. 905-914. http://dx.doi.org/10.1016/0092-8674(91)90397-H

[159] T. A. Comery, et al., "Abnormal Dendritic Spines in Fragile X Knockout Mice: Maturation and Pruning Deficits,” Proceedings of the National Academy of Sciences of the United States of America, Vol. 94, No. 10, 1997, pp. 54015404. http://dx.doi.org/10.1073/pnas.94.10.5401

[160] M. B. Ramocki and H. Y. Zoghbi, "Failure of Neuronal Homeostasis Results in Common Neuropsychiatric Phenotypes," Nature, Vol. 455, No. 7215, 2008, pp. 912-918. http://dx.doi.org/10.1038/nature07457

[161] N. Burnashev and A. Rozov, "Genomic Control of Receptor Function,” Cellular and Molecular Life Sciences, Vol. 57, No. 11, 2000, pp. 1499-1507.

[162] W. M. Gommans, S. P. Mullen and S. Maas, "RNA Editing: A Driving Force for Adaptive Evolution?” BioEssays, Vol. 31, No. 10, 2009, pp. 1137-1145.

[163] J. S. Mattick, R. J. Taft and G. J. Faulkner, “A Global View of Genomic Information-Moving beyond the Gene and the Master Regulator,” Trends in Genetics: TIG, Vol. 26, No. 1, 2009, pp. 21-28. http://dx.doi.org/10.1016/j.tig.2009.11.002 
[164] G. Barry, et al., “The Long Non-Coding RNA Gomafu Is Acutely Regulated in Response to Neuronal Activation and Involved in Schizophrenia-Associated Alternative Splicing,” Molecular Psychiatry, 2013. http://dx.doi.org/10.1038/mp.2013.45

[165] W. M. Gommans, S. P. Mullen and S. Maas, "RNA Editing: A Driving Force for Adaptive Evolution?” BioEssays, Vol. 31, No. 10, 2009, pp. 1137-1145.

[166] S. Y. Ng, R. Johnson and L. W. Stanton, "Human Long NonCoding RNAs Promote Pluripotency and Neuronal Differentiation by Association with Chromatin Modifiers and Transcription Factors,” The EMBO Journal, Vol. 31, No. 3, 2012, pp. 515-579. http://dx.doi.org/10.1038/emboj.2011.459

[167] G. Barry, et al., "The Long Non-Coding RNA Gomafu Is Acutely Regulated in Response to Neuronal Activation and Involved in Schizophrenia-Associated Alternative Splicing,” Molecular Psychiatry, 2013.

[168] C. Ernst and C. C. Morton, "Identification and Function of Long Non-Coding RNA,” Frontiers in Cellular Neuroscience, Vol. 7, 2013, p. 168. http://dx.doi.org/10.3389/fncel.2013.00168

[169] M. F. Pescosolido, et al., "Lighting a Path: Genetic Studies Pinpoint Neurodevelopmental Mechanisms in Autism and Related Disorders," Dialogues in Clinical Neuroscience, Vol. 14, No. 3, 2012, pp. 239-252.

[170] L. J. Kobrynski and K. E. Sullivan, "Velocardiofacial Syndrome, DiGeorge Syndrome: The Chromosome 22q11.2 Deletion Syndromes,” Lancet, Vol. 370, No. 9596, 2007, pp. 1443-1452. http://dx.doi.org/10.1016/S0140-6736(07)61601-8

[171]D. Gothelf, et al., "Risk Factors for the Emergence of Psychotic Disorders in Adolescents with 22q11.2 Deletion Syndrome," The American Journal of Psychiatry, Vol. 164, No. 4, 2007, pp. 663-669. http://dx.doi.org/10.1176/appi.ajp.164.4.663

[172] J. A. Lee and J. R. Lupski, "Genomic Rearrangements and Gene Copy-Number Alterations as a Cause of Nervous System Disorders," Neuron, Vol. 52, No. 1, 2006, pp. 103-121.

[173] D. Gothelf, et al., "Risk Factors for the Emergence of Psychotic Disorders in Adolescents with 22q11.2 Deletion Syndrome," The American Journal of Psychiatry, Vol. 164, No. 4, 2007, pp. 663-669.

[174] M. B. Ramocki and H. Y. Zoghbi, "Failure of Neuronal Homeostasis Results in Common Neuropsychiatric Phenotypes,” Nature, Vol. 455, 2008, pp. 912-918.

[175] I. Golding, J. Paulsson, S. M. Zawilski and E. C. Cox, "RealTime Kinetics of Gene Activity in Individual Bacteria," Cell, Vol. 123, No. 6, 2005, pp. 1025-1036. http://dx.doi.org/10.1016/j.cell.2005.09.031

[176] J. Yu, X. J. Ren, K. Q. Lao and X. S. Xie, "Probing Gene Expression in Live Cells, One Protein Molecule at a Time,” Science, Vol. 311, No. 5767, 2006, pp. 1600-1603. http://dx.doi.org/10.1126/science.1119623

[177] L. López-Maury, S. Marguerat and J. Bähler, “Tuning Gene Expression to Changing Environments: From Rapid Responses to Evolutionary Adaptation,” Nature Reviews.
Genetics, Vol. 9, No. 8, 2008, pp. 583-593.

http://dx.doi.org/10.1038/nrg2398

[178] M. Goldsmith and D. S. Tawfik, "Potential Role of Phenotypic Mutations in the Evolution of Protein Expression and Stability," Proceedings of the National Academy of Sciences of the United States of America, Vol. 106, No. 15, 2009, pp. 6197-6202. http://dx.doi.org/10.1073/pnas.0809506106

[179] B. Modrek and C. J. Lee, “Alternative Splicing in the Human, Mouse and Rat Genomes Is Associated with an Increased Frequency of Exon Creation and/or Loss," Nature Genetics, Vol. 34, No. 2, 2003, pp. 177-180. http://dx.doi.org/10.1038/ng1159

[180] W. M. Gommans, S. P. Mullen and S. Maas, "RNA Editing: A Driving Force for Adaptive Evolution?” BioEssays, Vol. 31, No. 10, 2009, pp. 1137-1145.

[181] V. R. Nelson and J. H. Nadeau, "Transgenerational Genetic Effects,” Epigenomics, Vol. 2, No. 6, 2010, pp. 797806. http://dx.doi.org/10.2217/epi.10.57

[182] R. M. Alcazar, R. Lin and A. Z. Fire, "Transmission Dynamics of Heritable Silencing Induced by Double-Stranded RNA in Caenorhabditis elegans," Genetics, Vol. 180, No. 3, 2008, pp. 1275-1288. http://dx.doi.org/10.1534/genetics.108.089433

[183] E. Jablonka and G. Raz, “Transgenerational Epigenetic Inheritance: Prevalence, Mechanisms, and Implications for the Study of Heredity and Evolution,” The Quarterly Review of Biology, Vol. 84, No. 2, 2009, pp. 131-176. http://dx.doi.org/10.1086/598822

[184] P. A. Jones and D. Takai, "The Role of DNA Methylation in Mammalian Epigenetics,” Science, Vol. 293, No. 5532, 2001, pp. 1068-1070. http://dx.doi.org/10.1126/science.1063852

[185] A. P. Feinberg and R. A. Irizarry, "Evolution in Health and Medicine Sackler Colloquium: Stochastic Epigenetic Variation as a Driving Force of Development, Evolutionary Adaptation, and Disease," Proceedings of the National Academy of Sciences of the United States of America, Vol. 107, Suppl. 1, 2010, pp. 1757-1764. http://dx.doi.org/10.1073/pnas.0906183107

[186] M. E. Feder, "Evolvability of Physiological and Biochemical Traits,” The Journal of Experimental Biology, Vol. 210, No., 2007 pp. 1653-1660.

[187] H. H. Kazazian, "Mobile Elements: Drivers of Genome Evolution,” Science, Vol. 303, No. 5664, 2004, pp. 16261632. http://dx.doi.org/10.1126/science.1089670

[188] J. A. Bailey, G. Liu and E. E. Eichler, “An Alu Transposition Model for the Origin and Expansion of Human Segmental Duplications,” American Journal of Human Genetics, Vol. 73, No. 4, 2003, pp. 823-834.

http://dx.doi.org/10.1086/378594

[189] G. Liu, et al., “Analysis of Primate Genomic Variation Reveals a Repeat-Driven Expansion of the Human Genome,” Genome Research, Vol. 13, No. 3, 2003, pp. 358-368. http://dx.doi.org/10.1101/gr.923303

[190] M. Brune, “Schizophrenia-An Evolutionary Enigma?” Neuroscience and Biobehavioral Reviews, Vol. 28, No. 1, 2004, pp. 41-53. 
http://dx.doi.org/10.1016/j.neubiorev.2003.10.002

[191] J. van Dongen and D. I. Boomsma, "The Evolutionary Paradox and the Missing Heritability of Schizophrenia," American Journal of Medical Genetics. Part B, Neuropsychiatric Genetics: The Official Publication of the International Society of Psychiatric Genetics, Vol. 162, No. 2, 2013, pp. 122-136.

http://dx.doi.org/10.1002/ajmg.b.32135

[192] R. M. Nesse, "Cliff-Edged Fitness Functions and the Persistence of Schizophrenia," Behavioral and Brain Sciences, Vol. 27, No. 6, 2004, pp. 862-863.

http://dx.doi.org/10.1017/S0140525X04300191

[193] J. Piven, P. Palmer, D. Jacobi, D. Childress and S. Arndt, "Broader Autism Phenotype: Evidence from a Family History Study of Multiple-Incidence Autism Families," American Journal of Psychiatry, Vol. 154, No. 2, 1997, pp. 185190.

[194] J. Piven, et al., "Personality and Language Characteristics in Parents from Multiple-Incidence Autism Families," American Journal of Medical Genetics, Vol. 74, No. 4, 1997, pp. 398-411.

http://dx.doi.org/10.1002/(SICI)1096-8628(19970725)74: 4<398::AID-AJMG11>3.0.CO;2-D

[195] P. R. Adriaens, "Debunking Evolutionary Psychiatry’s Schizophrenia Paradox,” Medical Hypotheses, Vol. 70, No. 6, 2008, pp. 1215-1222.

http://dx.doi.org/10.1016/j.mehy.2007.10.014

[196] J. Polimeni and J. P. Reiss, "Evolutionary Perspectives on Schizophrenia,” Canadian Journal of Psychiatry. Revue Canadienne de Psychiatrie, Vol. 48, No. 1, 2003, pp. 3439.

[197] G. Dodgson and S. Gordon, “Avoiding False Negatives: Are Some Auditory Hallucinations an Evolved Design Flaw?” Behavioural and Cognitive Psychotherapy, Vol. 37, No. 3, 2009, pp. 325-334. http://dx.doi.org/10.1017/S1352465809005244

[198] R. A. Power, et al., "Fecundity of Patients with Schizophrenia, Autism, Bipolar Disorder, Depression, Anorexia Nervosa, or Substance Abuse vs Their Unaffected Siblings,” JAMA Psychiatry, Vol. 70, No. 1, 2013, pp. 22-30. http://dx.doi.org/10.1001/jamapsychiatry.2013.268

[199] B. Spyropoulos, "Tay-Sachs Carriers and Tuberculosis Resistance,” Nature, Vol. 331, No. 6158, 1988, p. 666. http://dx.doi.org/10.1038/331666a0

[200] M. Carter and C. A. H. Watts, "Possible Biological Advantages among Schizophrenics’ Relatives,” The British Journal of Psychiatry, Vol. 118, No. 545, 1971, pp. 453-460. http://dx.doi.org/10.1192/bjp.118.545.453

[201] D. Nettle and H. Clegg, "Schizotypy, Creativity and Mating Success in Humans,” Proceedings of the Royal Society B: Biological Sciences, Vol. 273, No. 1586, 2006, pp. 611615. http://dx.doi.org/10.1098/rspb.2005.3349

[202] T. J. Crow, "Is Schizophrenia the Price That Homo sapiens Pays for Language?” Schizophrenia Research, Vol. 28, No. 2, 1997, pp. 127-141. http://dx.doi.org/10.1016/S0920-9964(97)00110-2

[203] J. H. MacCabe, I. Koupil and D. A. Leon, "Lifetime Reproductive Output over Two Generations in Patients with
Psychosis and Their Unaffected Siblings: The Uppsala 1915-1929 Birth Cohort Multigenerational Study,” Psychological Medicine, Vol. 39, No. 10, 2009, pp. 16671676. http://dx.doi.org/10.1017/S0033291709005431

[204] M. C. Keller and G. Miller, "Resolving the Paradox of Common, Harmful, Heritable Mental Disorders: Which Evolutionary Genetic Models Work Best?” Behavioral and Brain Sciences, Vol. 29, No. 4, 2006, pp. 385-404. http://dx.doi.org/10.1017/S0140525X06009095

[205] J. van Dongen and D. I. Boomsma, "The Evolutionary Paradox and the Missing Heritability of Schizophrenia," American Journal of Medical Genetics. Part B, Neuropsychiatric Genetics, Vol. 162B, No. 2, 2013, pp. 122-136.

[206] M. Brune, “Schizophrenia-An Evolutionary Enigma?” Neuroscience and Biobehavioral Reviews, Vol. 28, No. 1, 2004, pp. 41-53.

[207] R. E. Hoffman and T. H. McGlashan, "Synaptic Elimination, Neurodevelopment, and the Mechanism of Hallucinated 'Voices' in Schizophrenia," The American Journal of Psychiatry, Vol. 154, No. 12, 1997, pp. 1683-1689.

[208] J. van Dongen and D. I. Boomsma, "The Evolutionary Paradox and the Missing Heritability of Schizophrenia," American Journal of Medical Genetics. Part B, Neuropsychiatric Genetics, Vol. 162B, No. 2, 2013, pp. 122-136.

[209] J. K. Burns, “An Evolutionary Theory of Schizophrenia: Cortical Connectivity, Metarepresentation, and the Social Brain,” The Behavioral and Brain Sciences, Vol. 27, No. 6, 2004, pp. 831-855, discussion 855-885. http://dx.doi.org/10.1017/S0140525X04000196

[210] J. K. Burns, “An Evolutionary Theory of Schizophrenia: Cortical Connectivity, Metarepresentation, and the Social Brain,” The Behavioral and Brain Sciences, Vol. 27, No. 6, 2004, pp. 831-855. http://dx.doi.org/10.1017/S0140525X04000196

[211] E. Rees, V. Moskvina, M. J. Owen, M. C. O’Donovan and G. Kirov, "De Novo Rates and Selection of SchizophreniaAssociated Copy Number Variants," Biological Psychiatry, Vol. 70, No. 12, 2011, pp. 1109-1114. http://dx.doi.org/10.1016/j.biopsych.2011.07.011

[212] E. Rees, V. Moskvina, M. J. Owen, M. C. O’Donovan and G. Kirov, "De Novo Rates and Selection of SchizophreniaAssociated Copy Number Variants,” Biological Psychiatry, Vol. 70, No. 12, 2011, pp. 1109-1114. http://dx.doi.org/10.1016/j.biopsych.2011.07.011

[213] J. van Dongen and D. I. Boomsma, "The Evolutionary Paradox and the Missing Heritability of Schizophrenia," American Journal of Medical Genetics. Part B, Neuropsychiatric Genetics, Vol. 162B, No. 2, 2013, pp. 122-136.

[214] J. K. Pritchard, “Are Rare Variants Responsible for Susceptibility to Complex Diseases?” American Journal of $\mathrm{Hu}$ man Genetics, Vol. 69, No. 1, 2001, pp. 124-137. http://dx.doi.org/10.1086/321272

[215] M. C. Keller and G. Miller, "Resolving the Paradox of Common, Harmful, Heritable Mental Disorders," The Behavioral and Brain Sciences, Vol. 29, No. 4, 2006, pp. 385-404.

[216] J. M. McClellan, E. Susser and M. C. King, "Schizophrenia: A Common Disease Caused by Multiple Rare Alleles," 
The British Journal of Psychiatry: The Journal of Mental Science, Vol. 190, 2007, pp. 194-199. http://dx.doi.org/10.1192/bjp.bp.106.025585

[217] M. Y. M. Ng, et al., "Meta-Analysis of 32 Genome-Wide Linkage Studies of Schizophrenia,” Molecular Psychiatry, Vol. 14, No. 8, 2009, pp. 774-785.

http://dx.doi.org/10.1038/mp.2008.135

[218] J. van Dongen and D. I. Boomsma, "The Evolutionary Paradox and the Missing Heritability of Schizophrenia," American Journal of Medical Genetics. Part B, Neuropsychiatric Genetics, Vol. 162B, No. 2, 2013, pp. 122-136.

[219] M. C. Keller and G. Miller, "Resolving the Paradox of Common, Harmful, Heritable Mental Disorders,” The Behavioral and Brain Sciences, Vol. 29, No. 4, 2006, pp. 385-404.

[220] S. Baron-Cohen, "The Cognitive Neuroscience of Autism,” Journal of Neurology, Neurosurgery, and Psychiatry, Vol. 75, No. 7, 2004, pp. 945-948. http://dx.doi.org/10.1136/jnnp.2003.018713

[221] C. Chevallier, G. Kohls, V. Troiani, E. S. Brodkin and R. T. Schultz, "The Social Motivation Theory of Autism," Trends in Cognitive Sciences, Vol. 16, No. 4, 2012, pp. 231-239. http://dx.doi.org/10.1016/j.tics.2012.02.007

[222] M. Barbato, et al., "Social Cognition as a Mediator between Neurocognition and Functional Outcome in Individuals at Clinical High Risk for Psychosis,” Schizophrenia Research, Vol. 150, No. 2, 2013, pp. 542-546. http://dx.doi.org/10.1016/j.schres.2013.08.015

[223] A. K. Martin, et al., "Theory of Mind and the Social Brain: Implications for Understanding the Genetic Basis of Schizophrenia,” Genes, Brain, and Behavior, Vol. 13, No. 1, 2014, pp. 104-117. http://dx.doi.org/10.1111/gbb.12066

[224] M. M. Kjelgaard and H. Tager-Flusberg, “An Investiga- tion of Language Impairment in Autism: Implications for Genetic Subgroups,” Language and Cognitive Processes, Vol. 16, No. 2-3, 2001, pp. 287-308. http://dx.doi.org/10.1080/01690960042000058

[225] B. Crespi, P. Stead and M. Elliot, "Comparative Genomics of Autism and Schizophrenia," Proceedings of the National Academy of Sciences of the United States of America, Vol. 107, Suppl. 1, 2010, pp. 1736-1741. http://dx.doi.org/10.1073/pnas.0906080106

[226] M. Radanovic, et al., "Formal Thought Disorder and Language Impairment in Schizophrenia," Arquivos de NeuroPsiquiatria, Vol. 71, No. 1, 2013, pp. 55-60. http://dx.doi.org/10.1590/S0004-282X2012005000015

[227] E. L. Hill and U. Frith, "Understanding Autism: Insights from Mind and Brain,” Philosophical Transactions of the Royal Society of London. Series B: Biological Sciences, Vol. 358, No. 1430, 2003, pp. 281-289. http://dx.doi.org/10.1098/rstb.2002.1209

[228] S. Kalkstein, I. Hurford and R. C. Gur, "Neurocognition in Schizophrenia," Current Topics in Behavioral Neurosciences, Vol. 4, 2010, pp. 373-390. http://dx.doi.org/10.1007/7854_2010_42

[229] T. Kato, et al., "Genetic Variation Affects de Novo Translocation Frequency,” Science, Vol. 311, No. 5763, 2006, p. 971. http://dx.doi.org/10.1126/science.1121452

[230] J. R. Lupski, “Genomic Rearrangements and Sporadic Disease,” Nature Genetics, Vol. 39, 2007, pp. S43-S47.

[231] B. Crespi, P. Stead and M. Elliot, “Comparative Genomics of Autism and Schizophrenia," Proceedings of the National Academy of Sciences of the United States of America, Vol. 107, Suppl. 1, 2010, pp. 1736-1741.

[232] T. Walsh, et al., "Rare Structural Variants Disrupt Multiple Genes in Neurodevelopmental Pathways in Schizophrenia,” Science, Vol. 320, No. 5875, 2008, pp. 539-543. 